\title{
Biomechanical forces promote blood development through prostaglandin E2 and the CAMP-PKA signaling axis
}

\section{Citation}

Diaz, M. F., N. Li, H. J. Lee, L. Adamo, S. M. Evans, H. E. Willey, N. Arora, et al. 2015.

"Biomechanical forces promote blood development through prostaglandin E2 and the CAMPPKA signaling axis." The Journal of Experimental Medicine 212 (5): 665-680. doi:10.1084/ jem.20142235. http://dx.doi.org/10.1084/jem.20142235.

\section{Published Version}

doi:10.1084/jem.20142235

\section{Permanent link}

http://nrs.harvard.edu/urn-3:HUL.InstRepos:23845296

\section{Terms of Use}

This article was downloaded from Harvard University's DASH repository, and is made available under the terms and conditions applicable to Other Posted Material, as set forth at http:// nrs.harvard.edu/urn-3:HUL.InstRepos:dash.current.terms-of-use\#LAA

\section{Share Your Story}

The Harvard community has made this article openly available.

Please share how this access benefits you. Submit a story.

Accessibility 


\title{
Biomechanical forces promote blood development through prostaglandin $\mathrm{E}_{2}$ and the cAMP-PKA signaling axis
}

\author{
Miguel F. Diaz, ${ }^{1,2,3 *}$ Nan Li, ${ }^{1,2,3 *}$ Hyun Jung Lee, ${ }^{1,2,3}$ Luigi Adamo, ${ }^{4}$ \\ Siobahn M. Evans, ${ }^{1,2,3}$ Hannah E. Willey, ${ }^{5}$ Natasha Arora, ${ }^{6,7,8,9,10,11}$ \\ Yu-suke Torisawa, ${ }^{12,13,14}$ Dwayne A. Vickers, ${ }^{15}$ Samantha A. Morris, $, 6,7,8,9,10,11$ \\ Olaia Naveiras, ${ }^{6,7,8,9,10,11}$ Shashi K. Murthy, ${ }^{15}$ Donald E. Ingber, ${ }^{12,13,14}$ \\ George Q. Daley, ${ }^{6,7,8,9,10,11}$ Guillermo García-Cardeña, ${ }^{4,11}$ \\ and Pamela L. Wenzel ${ }^{1,2,3}$
}

\footnotetext{
'Program in Children's Regenerative Medicine, Department of Pediatric Surgery, ${ }^{2}$ Center for Stem Cell and Regenerative Medicine, The Brown Foundation Institute of Molecular Medicine, and ${ }^{3}$ mmmunology Program, Graduate School of Biomedical Sciences, University of Texas Health Science Center at Houston, Houston, TX 77030

${ }^{4}$ Center for Excellence in Vascular Biology, Department of Pathology, Brigham and Women's Hospital and Harvard Medical School, Boston, MA 02115

${ }^{5}$ Department of Bioengineering, Rice University, Houston, TX 77030

${ }^{6}$ Stem Cell Transplantation Program, ${ }^{7}$ Division of Pediatric Hematology and Oncology, ${ }^{8}$ Manton Center for Orphan Disease Research, and ${ }^{9}$ Howard Hughes Medical Institute, Children's Hospital Boston and Dana-Farber Cancer Institute, Boston, MA 02115

${ }^{10}$ Department of Biological Chemistry and Molecular Pharmacology, Harvard Medical School, Boston, MA 02115

${ }^{11}$ Harvard Stem Cell Institute and ${ }^{12}$ School of Engineering and Applied Sciences, Harvard University, Cambridge, MA 02138

${ }^{13}$ Wyss Institute for Biologically Inspired Engineering at Harvard University and ${ }^{14}$ Vascular Biology Program, Boston Children's Hospital and Harvard Medical School, Boston, MA 02115

${ }^{15}$ Barnett Institute of Chemical and Biological Analysis, Northeastern University, Boston, MA 02115
}

\section{CORRESPONDENCE}

Guillermo Garcia-Cardeña:

guillermo_garcia-cardena@

hms.harvard.edu

OR

George 0. Daley:

george.daley@

childrens.harvard.edu

OR

Pamela L. Wenzel:

pamela.I.wenzel@uth.tmc.edu

Abbreviations used: AGM, aorta-gonad-mesonephros; CREB, cAMP response elementbinding protein; $\mathrm{dmPGE}_{2}$ 16,16-dimethyl-PGE $\mathrm{PG}_{2}$ e.e., embryo equivalent; HSC, hematopoietic stem cell; NFAT, nuclear factor of activated T cells; $\mathrm{NO}$, nitric oxide; $\mathrm{PGE}_{2}$, prostaglandin $\mathrm{E}_{2}$; PKA, protein kinase A; PSp, paraaortic splanchnopleura; qRT-PCR, quantitative RT-PCR; WSS, wall shear stress.

Blood flow promotes emergence of definitive hematopoietic stem cells (HSCs) in the developing embryo, yet the signals generated by hemodynamic forces that influence hematopoietic potential remain poorly defined. Here we show that fluid shear stress endows long-term multilineage engraftment potential upon early hematopoietic tissues at embryonic day 9.5, an embryonic stage not previously described to harbor HSCs. Effects on hematopoiesis are mediated in part by a cascade downstream of wall shear stress that involves calcium efflux and stimulation of the prostaglandin $E_{2}\left(P G E_{2}\right)$-cyclic adenosine monophosphate (cAMP)-protein kinase $A(P K A)$ signaling axis. Blockade of the $\mathrm{PGE}_{2}-$ cAMP-PKA pathway in the aorta-gonad-mesonephros (AGM) abolished enhancement in hematopoietic activity. Furthermore, Ncx1 heartbeat mutants, as well as static cultures of AGM, exhibit lower levels of expression of prostaglandin synthases and reduced phosphorylation of the CAMP response element-binding protein (CREB). Similar to flow-exposed cultures, transient treatment of $A G M$ with the synthetic analogue 16,16-dimethyl-PGE 2 stimulates more robust engraftment of adult recipients and greater lymphoid reconstitution. These data provide one mechanism by which biomechanical forces induced by blood flow modulate hematopoietic potential.

The establishment of intra-aortic blood flow after initiation of the heartbeat coincides with a crucial period in development when a switch occurs from primitive to adult-type definitive hematopoiesis (Dzierzak and Speck, 2008). We and others have shown that the mechanical forces induced by blood flow play a fundamental role in the emergence and maintenance of

\footnotetext{
*M.F. Diaz and N. Li contributed equally to this paper.
}

hematopoietic stem cells (HSCs) and progenitors in the aorta-gonad-mesonephros (AGM) region (Adamo et al., 2009; North et al., 2009). Functional HSCs and precursors with potential for HSC formation (pre-HSCs) have been

2015 Diaz et at. This article is distributed under the terms of an AttributionNoncommercial-Share Alike-No Mirror Sites license for the first six months after the publication date (see http://www.rupress.org/terms). After six months it is available under a Creative Commons License (Attribution-Noncommercial-Share Alike 3.0 Unported license, as described at http://creativecommons.org/licenses/ by-nc-sa/3.0/). 
found to arise mainly at arterial sites of the embryonic vasculature (Gordon-Keylock et al., 2013). Mutant embryos of the mouse and fish that lack a heartbeat, and thereby have reduced blood flow, exhibit a dramatic reduction in intravascular hematopoietic clusters and definitive hematopoietic activity in the AGM, further implicating mechanical forces as critical regulators of HSC emergence and/or expansion (Adamo et al., 2009; North et al., 2009; Wang et al., 2011). Wall shear stress (WSS), or the frictional force parallel to cells of the vessel wall, activates genes essential for arterial specification and definitive hematopoiesis in the developing embryo (Adamo et al., 2009). Nitric oxide (NO) signaling contributes to the induction of HSC formation by blood flow, and stimulation of this pathway either by mechanical forces or pharmacological treatment with NO donors can rescue hematopoiesis in embryos without a heartbeat (Adamo et al., 2009; North et al., 2009; Wang et al., 2011). In addition to NO, several other autacoids, including prostacyclins, are modulated by shear stress and influence fundamental properties of endothelial and smooth muscle function (Frangos et al., 1985; Alshihabi et al., 1996; Johnson et al., 1996; Topper et al., 1996; Smalt et al., 1997; Tsai et al., 2009). Their role in determination of hematopoietic fate remains poorly characterized.

Recently, several groups have shown that prostaglandin $\mathrm{E}_{2}\left(\mathrm{PGE}_{2}\right)$, a prostacyclin-related prostanoid family member, regulates HSC and progenitor self-renewal, survival, trafficking, and engraftment potential and has led to the development of methods for expansion of hematopoietic cells for clinical use (North et al., 2007; Cutler et al., 2013; Hoggatt et al., 2013a,b; Porter et al., 2013). Ptgs2 is the gene that encodes the limiting enzyme in $\mathrm{PGE}_{2}$ production, COX2, and was recently identified in differential expression analysis as the second most highly up-regulated gene, second only to Fosb, in AGM-derived HSCs as compared with HSCs present in the fetal liver (McKinney-Freeman et al., 2012). Goessling et al. (2009) determined that the synthetic analogue 16,16-dimethyl$\mathrm{PGE}_{2}\left(\mathrm{dmPGE}_{2}\right)$ could enhance HSC formation in developing zebrafish embryos through cAMP-protein kinase A (PKA) modulation of Wnt signaling. Independent studies further implicate cAMP-PKA in initiation of vascular and hematopoietic differentiation of embryonic stem cells via recruitment of the transcriptional activator cAMP response element-binding protein (CREB) to the Etv 2 promoter, resulting in up-regulation of vascular growth factor receptors and hematopoietic transcription factors including Flk1, Tie2, Scl/Tal1, and Gata2 (Yamamizu et al., 2012). Connections between these signaling pathways and fluid flow have been described in osteolineages of the bone but have not yet been investigated in blood development (Ogasawara et al., 2001; Ogawa et al., 2014).

Here, we demonstrate that WSS associated with embryonic blood flow potentiates development of definitive hematopoietic cells through the induction of developmental pathways known to be critical for hematopoiesis, including Wnt and Notch, as well as stimulating mechanosensors that trigger calcium flux. Signaling through calcium up-regulated expression of the COX2 gene, Ptgs2. Subsequent increases in $\mathrm{PGE}_{2}$ biosynthesis and cAMP-PKA activity were necessary for expansion of nascent HSCs and progenitors. Phosphorylation of CREB, presumably by PKA, was associated with transcription of genes containing the cAMP response element. WSS and $\mathrm{dmPGE}_{2}$ were each capable of promoting long-term multilineage hematopoietic reconstitution and lymphoid lineage potential from the paraaortic splanchnopleura (PSp) and AGM, respectively. This work directly links mechanical forces generated by blood flow to the regulation of biochemical and genetic pathways that define HSC potential during embryonic hematopoiesis.

\section{RESULTS \\ Functional maturity of hematopoietic stem and progenitor cells is enhanced by WSS}

Previously, we described specific characteristics of WSS that induce hematopoietic progenitor activity in two-dimensional adherent cultures of dissociated AGM (Adamo et al., 2009). In the present study, we hypothesized that WSS may play a role in specification of HSCs that support life-long adult hematopoiesis and so examined developmental time points that precede definitive HSC emergence in cells derived from the anlage of the AGM known as the PSp at embryonic day (E) 9.5 and from the AGM at E10.5. Runx1 and Myb, two master regulators of hematopoiesis, are transcriptionally up-regulated by shear stress typical of embryonic murine blood flow $\left(5 \mathrm{dyn} / \mathrm{cm}^{2}\right)$, as are other genes required for definitive hematopoiesis and lymphopoiesis, including Bcl11a, Etv6, Gata2, Gata3, Tff, Rag1, and Rag2 (Fig. 1 A). Analysis of cell surface phenotype after WSS confirmed increases in two markers of hemogenic endothelium, CD144/VE-Cadherin and c-kit, in the live (DAPI ${ }^{-}$) population (Fig. 1 B). We observed a $5.2 \pm 1.2$-fold increase in the percentage of CD144 ${ }^{+} \mathrm{ckit}^{+}$cells, a surface phenotype thought to distinguish a subset of endothelial cells with definitive HSC potential (Fig. 1 C; Eilken et al., 2009; Swiers et al., 2013).

E9.5 PSp has previously been found to produce primarily B1a lymphocyte progenitors when delivered into immunocompromised neonatal recipients (Yoshimoto et al., 2011) or intact under the adult kidney capsule (Godin et al., 1993) and requires whole organ culture for several days to acquire longterm multilineage repopulating activity in vivo (Cumano et al., 2001). To evaluate whether changes induced by WSS were capable of producing greater functional competence in stem and progenitor cells, we transplanted dissociated PSp from E9.5 embryos (21-29 somite pairs) cultured with or without WSS for $36 \mathrm{~h}$ into irradiated adult $\operatorname{Rag} 2^{-1-} I l 2 r \boldsymbol{\gamma}^{-1-}$ recipients. Based upon the expectation that dissociated E9.5 PSp would provide absent to scant engraftment of adult recipients long term (Godin et al., 1993; Cumano et al., 2001), we transplanted each recipient with 16 embryo equivalents (e.e.). We detected low-level engraftment in the peripheral blood of 4 of 17 animals injected with E9.5 PSp cultured under static conditions, which dropped further by $10 \mathrm{wk}$ in the surviving 10 animals, suggesting that the majority of engrafting cells were exhaustible short-term progenitors (Fig. 2, A and B). At $20 \mathrm{wk}$, static cultures contributed to $<1.4 \%$ of total peripheral 

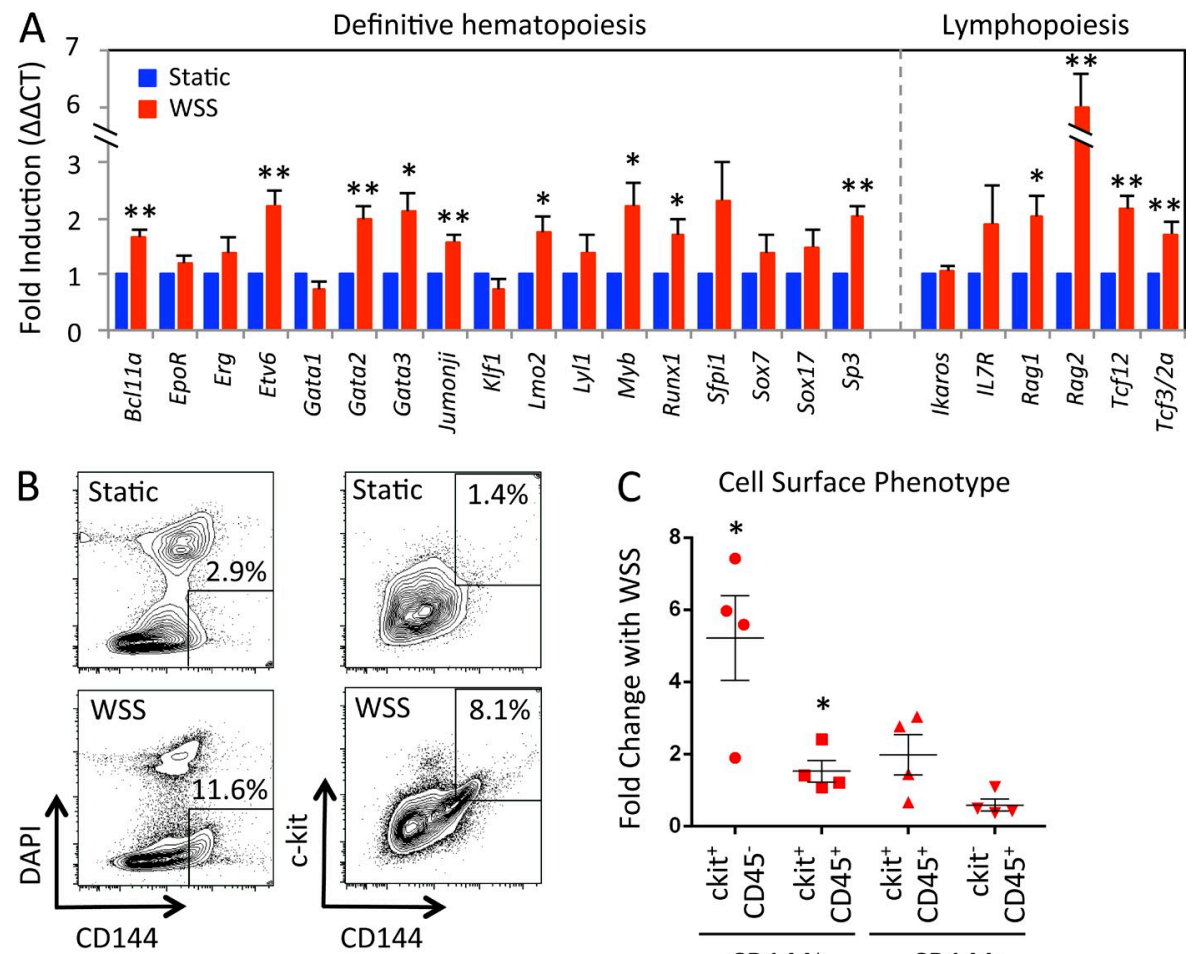

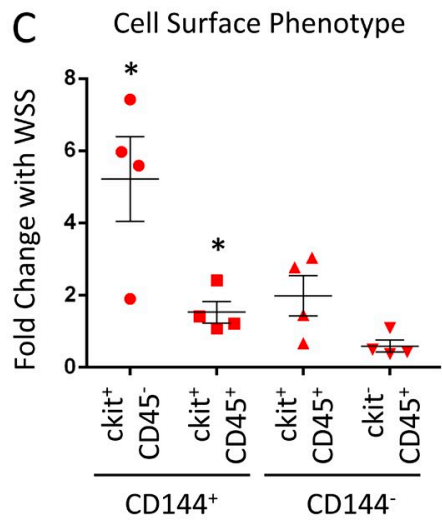

Figure 1. WSS induces hematopoietic gene expression and progenitor activity. E9.5 PSp- or E10.5 AGM-derived cells were cultured for $36 \mathrm{~h}$ in the presence of $5 \mathrm{dyn} / \mathrm{cm}^{2}$ WSS or static $\left(<0.0001 \mathrm{dyn} / \mathrm{cm}^{2}\right)$ conditions. (A) qRT-PCR of E9.5 PSp demonstrates that WSS induces widespread up-regulation of genes known to be critical regulators of definitive hematopoiesis and lymphopoiesis ( $n=5$ independent experiments; two-tailed Student's $t$ test or Mann-Whitney rank sum: ${ }^{*}, \mathrm{P}<0.05 ;{ }^{* *}, \mathrm{P}<0.01$ ). (B) Representative flow cytometry plots show distribution of hemogenic endothelial markers (CD144/ VE-Cadherin and c-kit) in the cultured populations after $36 \mathrm{~h}$ of WSS exposure. Live $\left(\mathrm{DAPI}^{-}\right) \mathrm{CD} 144^{+}$and $\mathrm{CD} 144^{+} \mathrm{ckit}^{+}$gates are depicted. (C) CD144+ ckit $^{+} \mathrm{CD} 45^{-1+}$ populations are increased by WSS $(n=4$ independent experiments; two-tailed Student's $t$ test: ${ }^{*}, \mathrm{P}<$ $0.05)$. Data are represented as mean \pm SEM. blood leukocytes in all but one recipient $\left(2.8 \% \mathrm{CD} 45.2^{+}\right)$. In contrast, WSS produced higher initial engraftment levels in 6 of 15 recipients, which persisted long term in 5 animals (Fig. 2 B). PSp contributed to major adult blood lineages, including B lymphoid (B220, CD19, and IgM), T lymphoid (CD3, CD4, and CD8), and myeloid (Mac1 and Gr1) populations (Fig. $2 \mathrm{C}$ ). WSS exposure promoted earlier emergence of B lymphocytes and sustained B lymphopoiesis in the periphery beyond $20 \mathrm{wk}$ (Fig. 2, D and E). Greater B cell maturity was also apparent in the bone marrow (Fig. 2 F). Specifically, greater numbers of cells were in stages of pre-pro- and pro-B commitment $\left(\mathrm{B} 220^{+}\right.$ $\mathrm{CD}_{4}{ }^{+}$), with modest increases in late-stage pre-B and $\mathrm{B}$ development $\left(\mathrm{B} 220^{+} \mathrm{CD} 43^{-}\right)$typical of adult-type bone marrow progenitors (Fig. 2 G; Hardy and Hayakawa, 1991). CD45.2 $2^{+}$ bone marrow cells were subsequently transferred to secondary recipients and found to reconstitute four of seven WSS and two of five static recipients (Fig. 3, A and B). Importantly, peak chimerism was substantially higher for three of the WSS donors $(4.2 \%, 12.2 \%$, and $61.3 \%)$ as compared with static donors $(0.9 \%$ and $2.1 \%$ ). B and $\mathrm{T}$ cells were detectable as discrete populations and persisted long term in WSS recipients (Fig. 3, C and D). Collectively, these data suggest that WSS serves as a critical developmental signal that promotes commitment of precursors to the blood lineage and endows nascent HSCs and progenitors with the functional competence necessary to engraft the adult hematopoietic niche.

\section{WSS is required for proper developmental signaling}

Knockout of the Ncx1 gene that encodes the cardiac-specific sodium/calcium exchanger results in mutant embryos with no heartbeat and little to no hematopoietic progenitor activity (Lux et al., 2008). Development of mutant embryos proceeds up to $10 \mathrm{~d}$ of gestation, at which time cardiac defects result in embryonic lethality. Previously, we showed that hematopoietic activity could be rescued ex vivo after $36 \mathrm{~h}$ of WSS in cells derived from E9.5 Ncx $1^{-/-}$PSp (Adamo et al., 2009). We therefore hypothesized that hemogenic endothelium was present in $N c x 1^{-1-}$ PSp and measured the frequency of cell surface markers typical of hematopoietic precursors and progeny. We found that $N c x 1^{-/-}$embryos harbor phenotypic hemogenic endothelium and hematopoietic cells (Fig. 4 A). Indeed, the frequency of CD $144^{+} \mathrm{ckit}^{+} \mathrm{CD} 45^{-}$hemogenic endothelium was elevated in mutant PSp by $\sim 4.1 \pm 1.1-$ fold (Fig. 4 B). As this contrasts with our observations of enhanced CD $144^{+}$ckit $^{+} \mathrm{CD}^{-} 5^{-}$cell production in ex vivo WSS cultures, we speculate that accumulation of hemogenic endothelial cells in the mutant PSp could be a consequence of defective circulation, a phenomenon demonstrated previously to lead to pooling of primitive erythrocytes during development of zebrafish embryos (Iida et al., 2010). We thus analyzed gene expression in $N c x 1^{-/-}$PSp and found decreases in Runx1, Gata2, Tal1, Etv2, and effectors of Notch (Hes1 and Hey1) and Wnt (Wnt3a and Lef1), supporting a role for WSS in determination of signaling events in the PSp (Fig. 4 C).

We and others previously identified NO as a critical regulator of hematopoietic progenitor expansion in response to WSS and blood flow (Adamo et al., 2009; North et al., 2009; Wang et al., 2011). To more precisely define the signaling mechanisms triggered by WSS, we conducted global gene expression profiling of ex vivo cultures of AGM. Notch, Wnt, 

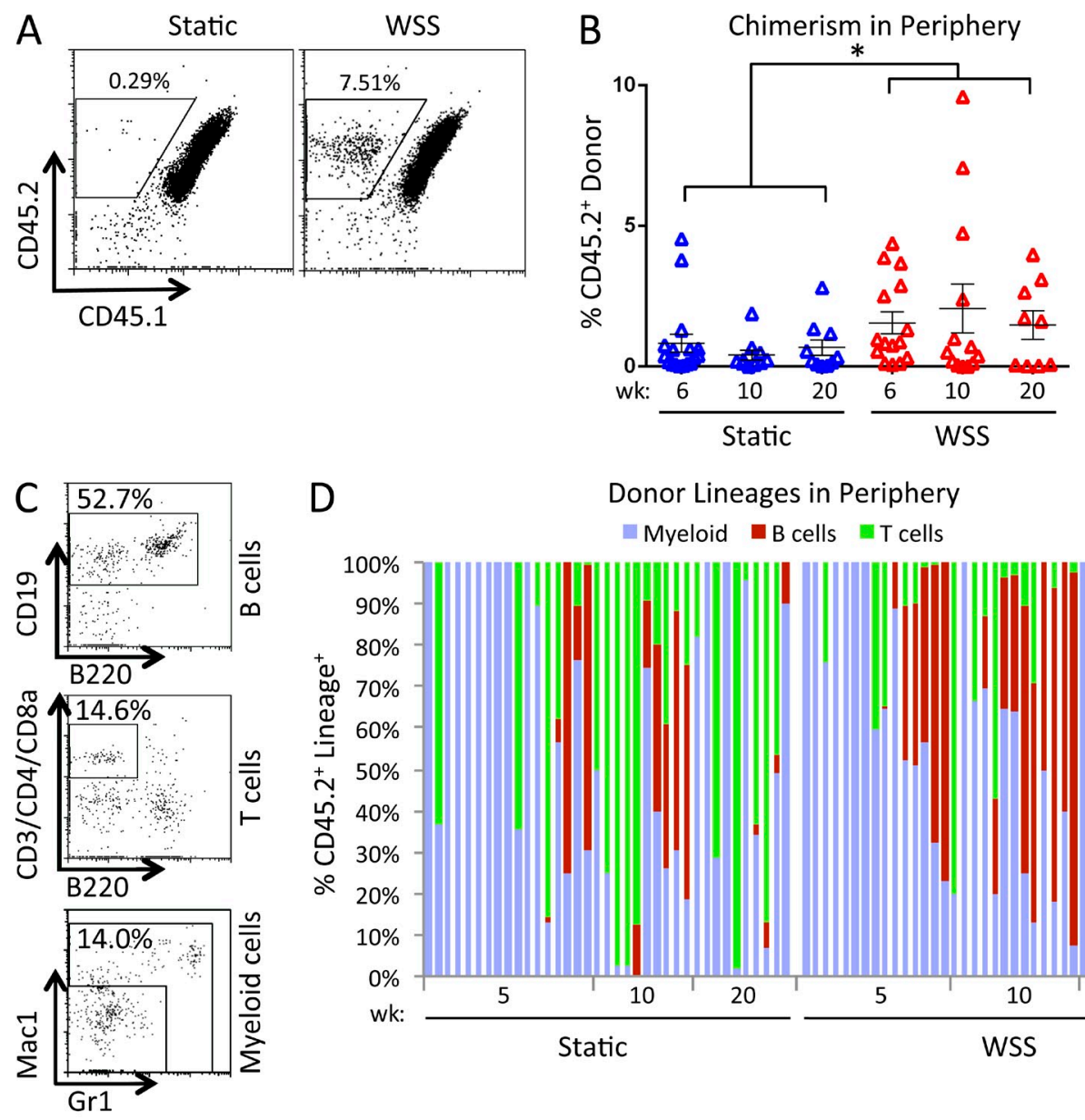

D

Donor Lineages in Periphery
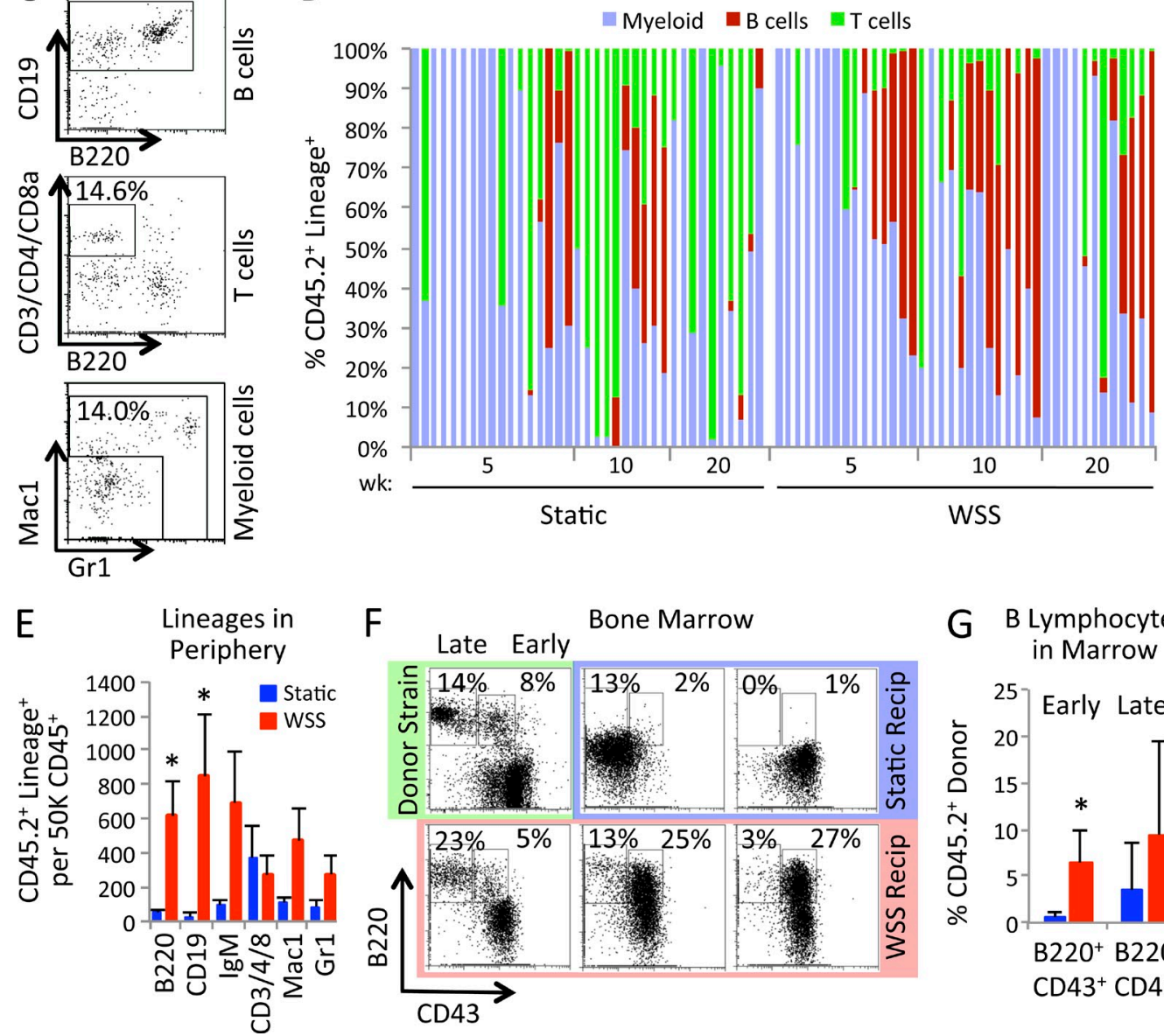

$\mathrm{F}$

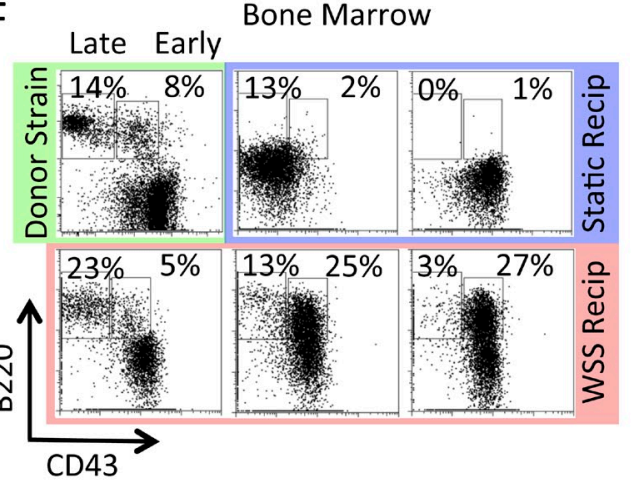

G B Lymphocytes in Marrow

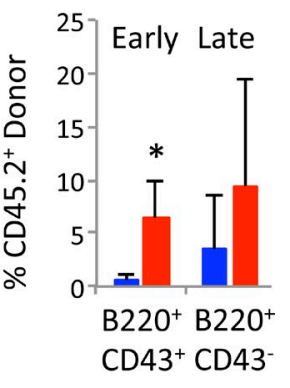

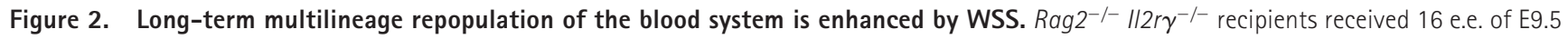
PSp cultured in the presence of either static $\left(<0.0001 \mathrm{dyn} / \mathrm{cm}^{2}\right)$ or WSS $\left(5 \mathrm{dyn} / \mathrm{cm}^{2}\right)$ conditions for $36 \mathrm{~h}$. (A) Donor contribution to recipient leukocytes in peripheral blood is distinguishable as a discrete CD45.2+ CD 45.1- population in WSS recipients (20-wk posttransplantation data shown). (B) Peripheral blood reconstitution is significantly greater from cells exposed to WSS ( $n=17$ static from six independent experiments, $n=15$ WSS from seven independent experiments; two-way ANOVA: ${ }^{*}, P=0.03$ ). (C) Representative flow cytometry plots from the WSS recipient in A show lineage ${ }^{+}$engraftment from CD45.2+ donor-derived cells. (D) Lineages present in CD45.2+ donor peripheral blood from individual recipients at 5, 10, and 20 wk after transplantation. B lymphopoiesis and long-term multilineage potential are bolstered by WSS. (E) CD45.2+ donor PSps contribute to greater numbers of cells expressing B lineage markers during the posttransplant period (20 wk) when exposed to WSS ( $n=17$ static, $n=15$ WSS; Mann-Whitney rank sum: $\left.{ }^{*}, P=0.03\right)$. (F) Primary recipient bone marrow was analyzed at 20 wk after transplantation of cultured PSp with markers of $B$ lineage maturation (two static and three WSS recipients are shown alongside adult donor strain). B cells within the bone marrow collected from WSS recipients resemble adult donor marrow. (G) Production of early and late B lineages in primary bone marrow was discriminated by B220 and CD43 cell surface expression in the CD45.2+ donor population. Early B lineage phenotypes were marginally elevated by WSS (B220 ${ }^{+}$CD $43^{+}: n=3$ static, $n=5$ WSS; unpaired Student's $t$ test: $\left.{ }^{*}, P=0.13\right)$. Data are represented as mean \pm SEM. 
A

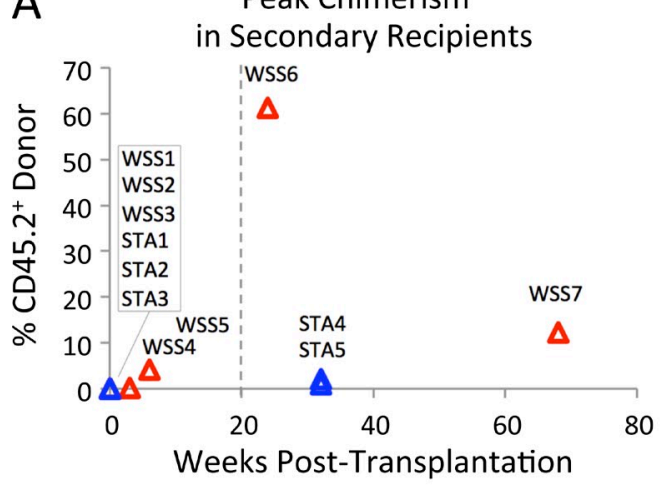

B
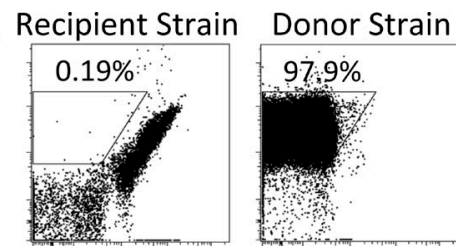

Static-2ndary WSS-2ndary
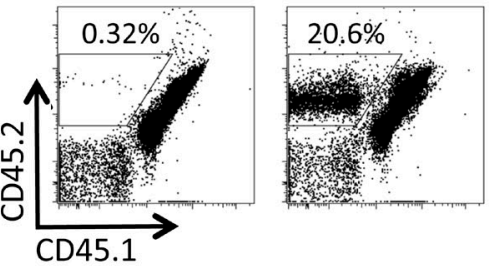

C

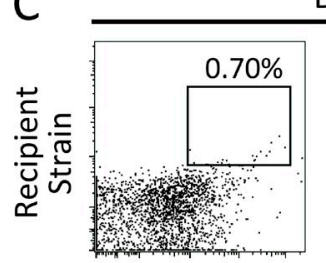

B cells
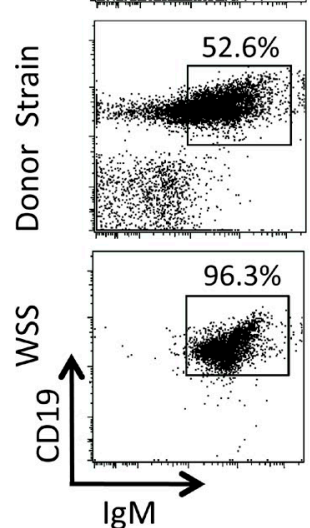

IgM
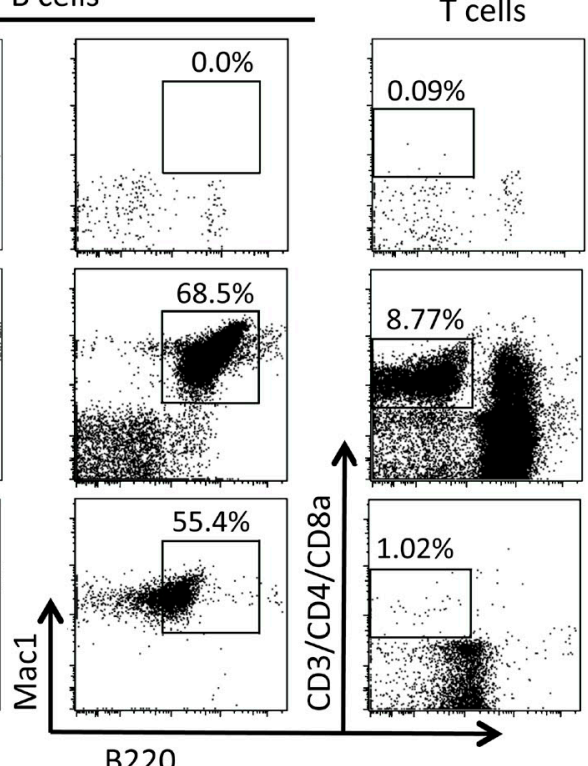

B220
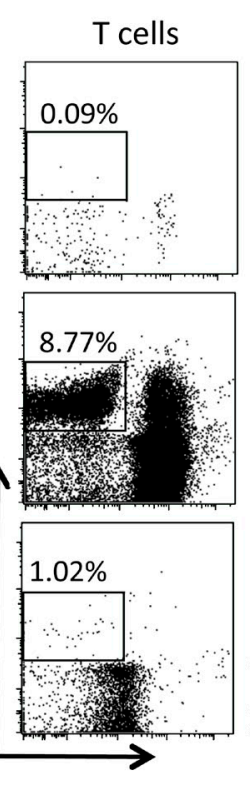

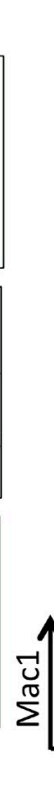

Myeloid cells
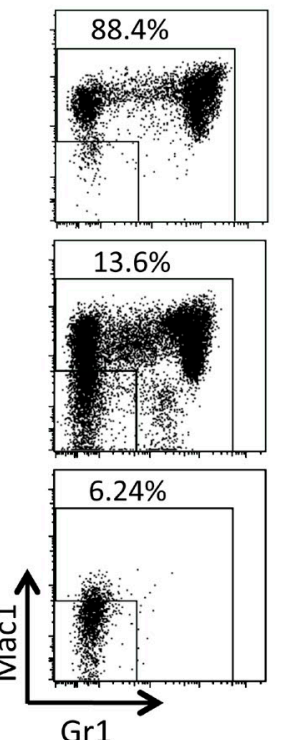

Figure 3. WSS enhances long-term secondary engraftment. Secondary recipients received $20,000 \mathrm{CD} 45.2^{+}$bone marrow cells sorted from primary recipients plus 200,000 CD45.1 $1^{+}$CD45.2 $2^{+}$Rag2 $2^{-1-} / 12 \mathrm{r}^{-/-}$competitor bone marrow cells. (A) Engraftment in the periphery of secondary recipients was monitored for up to $10 \mathrm{mo}$ ( $n=5$ static, $n=7$ WSS from independent primary recipients). Peak chimerism was found long term in two WSS and two static recipients, with substantially higher donor contribution in the WSS recipients. Long-term engraftment was defined as CD45.2 positivity in the periphery for $>20$ wk (denoted by the dashed line) at any level above background. (B) Plots of peripheral blood collected from recipients 8 mo after transplantation illustrate sustained contribution of donorderived CD45.2+ marrow cells. (C) Analysis of lineages present in the $C D 45.2^{+}$gate of the engrafted WSS recipient depicted in panel B alongside adult peripheral blood from the donor and recipient strains. (D) Lineages present in CD45.2+ donor peripheral blood from individual secondary recipients at $4,24,36$, 48 , and 68 wk after transplantation. Recipient strain is represented by an untransplanted adult CD $45.1^{+}$CD 45.2 $2^{+}$Rag2 $2^{-/-} / 12 \mathrm{r}^{-/-}$; donor strain is adult Swiss Webster.

\section{Donor Lineages in Periphery}

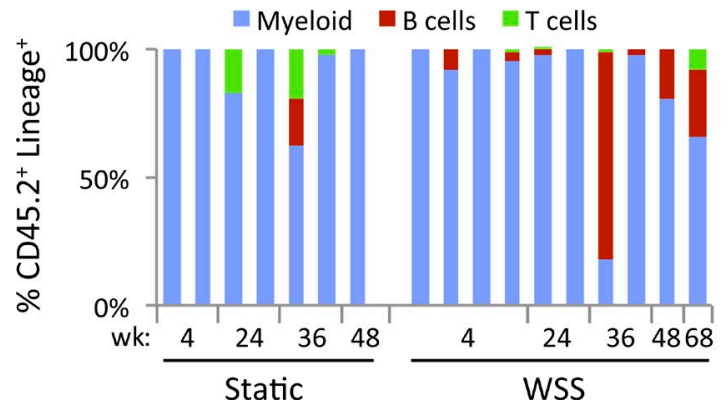

and eicosanoid signaling have previously been found in proteomic analyses to respond rapidly to fluid shear stress in aortic endothelial cells (Wang et al., 2007). Informed by these studies and our own serial measurements of gene subsets, we selected an early time point $(6 \mathrm{~h})$ and one demonstrated previously to enhance hematopoietic activity $(36 \mathrm{~h})$ to perform global gene expression analysis (Adamo et al., 2009). In brief, WSS was applied to dissociated E10.5 AGM cultured within microfluidic channels as described previously (Li et al., 2014), replicates were lysed, and RNA was processed for analysis by Illumina Mouse WG-6 v2.0 Expression BeadChips (45,200 transcripts). Unsupervised hierarchical clustering of unfiltered genes positioned 6- and 36-h cultures in two distinct groups, followed by segregation of static and WSS cultures (not depicted). Differential gene expression analysis $(\mathrm{P}<0.01$, twofold threshold) revealed significant change in 1,435 unique 
A

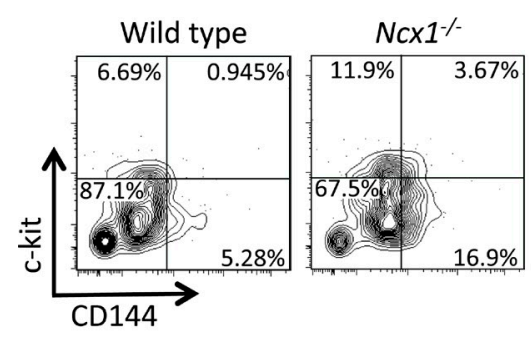

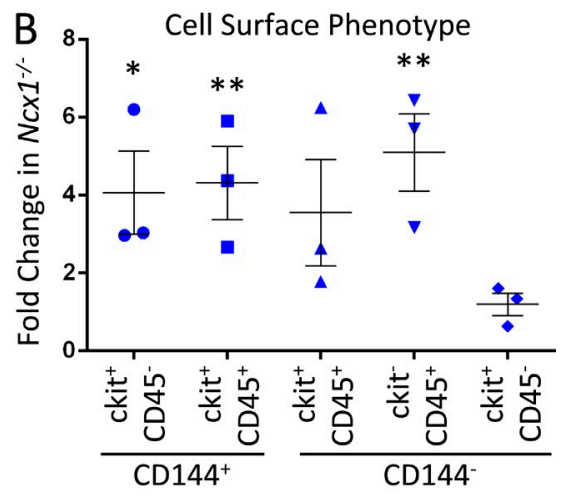

C $\left.{ }^{2.0}\right] \quad$ Gene Expression Analysis of Ncx 1 - PSp

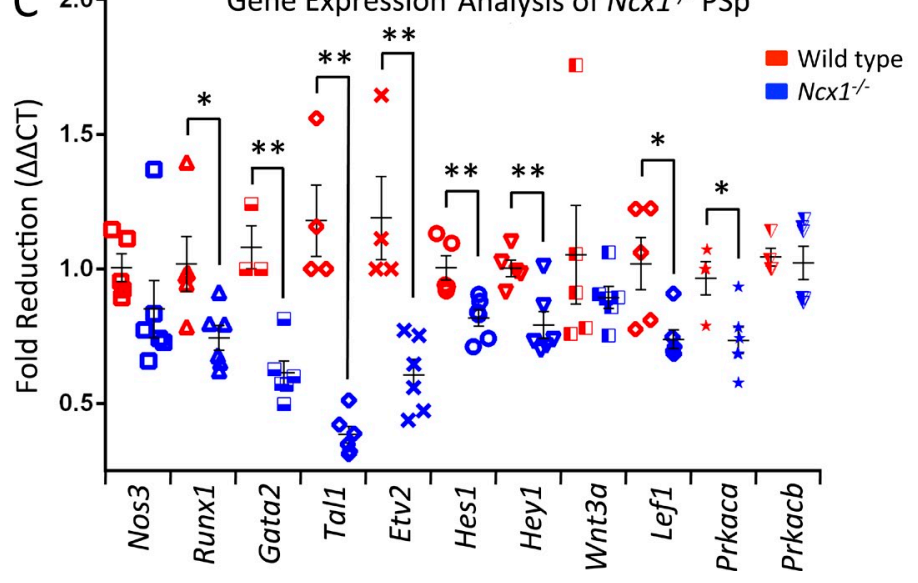

Figure 4. Hemogenic precursors of Ncx1 mutant embryos lack instructive signaling from Runx1, Notch, and Wnt. (A) E9.5 PSps were isolated from individual embryos and profiled for cell surface markers after dissociation. (B) Quantification of populations within Ncx 1 mutant embryos showed elevated percentages of hemogenic endothelial and hematopoietic cells, reflecting an ability to specify blood lineages but an impairment in the cells ability to leave the PSp because of lack of circulation. Frequency of hemogenic populations is elevated in $\mathrm{Nc} 1^{-1-}$ mutants $(n=5$ wild-type littermates, $n=3 \mathrm{Nc} \times 1^{-1-}$; unpaired Student's $t$ test: $\left.{ }^{*}, \mathrm{P}=0.015 ;{ }^{*}, \mathrm{P}<0.006\right)$. (C) $\mathrm{Nc} \times 1^{-1-}$ embryos express aberrantly low levels of critical regulators of hematopoiesis. Transcripts of key developmental pathways are reduced in $\mathrm{Nc} \times 1^{-1-} \mathrm{PSp}$ ( $n=4-6$ wild-type littermates, $n=5-6 \mathrm{Nc}^{1-1^{-1-}}$; two-tailed Student's $t$ test: ${ }^{*}, \mathrm{P}<0.03 ;{ }^{* *}, \mathrm{P}<0.009$ ). Error bars represent SEM. transcripts at $6 \mathrm{~h}, 347$ at $36 \mathrm{~h}$, and 109 common to both time points (Fig. $5 \mathrm{~A}$ and Dataset S1). By Ingenuity pathway analysis, these genes were found to encode enzymes and transcription regulators required for signaling through several overlapping pathways, including G protein-coupled receptors (GPCRs), calcium transport, nuclear factor of activated T cells (NFAT), phospholipase C, and PI3K (Btk, Chp1, Nfatc3, and Plcb3; Fig. $5 \mathrm{~B}$ ). Components of the NFKB signaling pathway were also enriched, including the TRAF family member associated $\mathrm{NF \kappa B}$ activator (Tank) and IKB $\varepsilon$ regulatory subunit (Nfkbie). Several other kinases, enzymes, and transcription factors were found to contribute to signaling through CREB, such as the $\alpha$ regulatory subunit of cAMP-dependent protein kinase (Prkar1a), G protein-binding protein (Gnb1), Creb5, and CREBbinding protein $(C r e b b p)$. Wnt/ $\beta$-catenin regulators and ligands were also enriched (Akt3,Dkk1,Wnt1, and $W n t 7 b)$. Functional enrichment analysis of unfiltered genes by GSEA (Mootha et al., 2003; Subramanian et al., 2005) was used to construct a global network wherein overlapping gene sets clustered together (Merico et al., 2010) and connections between pathways could be visualized at 6 and $36 \mathrm{~h}$ in parallel (Fig. $5 \mathrm{C}$ ). Wnt signaling functionally clustered with the adaptive immune system and cell cycle, whereas Notch, TGF- $\beta$, and EGFR/ CREB/MAPK clustered as distinct groups. Notably, several functional groups that emerged from network analysis are known regulators or effectors of prostaglandin production and signaling, including calcium, MAPK, CREB, Wnt, NFKB, and biological oxidation involving prostaglandin-endoperoxide synthase function of COX1 and COX2 (Ptgs1 and Ptgs2; Fig. 5 C and Dataset S2; Tsatsanis et al., 2006; Goessling et al., 2011).

\section{Calcium efflux propagates a signaling cascade downstream} of WSS that amplifies prostaglandin synthesis

$\mathrm{PGE}_{2}$ has recently been documented to promote hematopoietic engraftment in mice and in human clinical trials (North et al., 2007; Hoggatt et al., 2009, 2013a,b; Cutler et al., 2013). Up-regulation of prostaglandin synthases Ptgs1, Ptgs2, Ptges, and Ptges3, as well as Wnt and Notch were verified by quantitative RT-PCR (qRT-PCR) in WSS-exposed populations of the E10.5 AGM, including the CD144+ ${ }^{+} \mathrm{CD} 45^{-}$population identified as the hemogenic endothelium (Fig. 6, A and B). Importantly, we found that WSS promoted production and secretion of significantly higher levels of $\mathrm{PGE}_{2}$ (Fig. 6 C).This enhanced $\mathrm{PGE}_{2}$ production could be blocked by the COX1/2 antagonist indomethacin and the COX2-specific inhibitors NS-398 and CAY10404, suggesting that Ptgs2 up-regulation may be responsible for elevated $\mathrm{PGE}_{2}$ production in WSSexposed AGM (Fig. 6 D). In osteoblasts, calcium-dependent activity at focal adhesions is believed to regulate COX2 and $\mathrm{PGE}_{2}$ synthesis (Ponik and Pavalko, 2004). We therefore hypothesized that WSS may also stimulate calcium flux upstream of $\mathrm{PGE}_{2}$ production in the AGM. Live cell imaging with Fluo-4 AM confirmed sparks of intracellular calcium signaling in WSS-stimulated cells, as determined by increased intensity in 
A

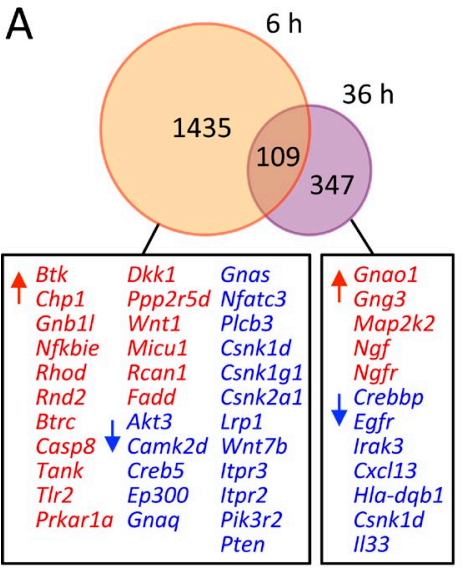

B

\begin{tabular}{lll} 
Ingenuity Canonical Pathways & Ratio & P-value \\
\hline $6 \mathrm{~h}$ & & \\
\hline PI3K Signaling in B Lymphocytes & 0.140 & 0.002 \\
Calcium Signaling & 0.125 & 0.003 \\
Gaq Signaling & 0.125 & 0.005 \\
Role of NFAT in Regulation of the Immune & 0.122 & 0.005 \\
Response & 0.112 & 0.014 \\
NF-KB Signaling & 0.104 & 0.018 \\
Phospholipase C Signaling & 0.106 & 0.030 \\
CREB Signaling in Neurons & 0.105 & 0.032 \\
Wnt/B-catenin Signaling & & \\
36 h & 0.040 & 0.014 \\
\hline NF-KB Signaling & 0.045 & 0.041 \\
Altered T Cell and B Cell Signaling in Rheumatoid & & \\
Arthritis & 0.035 & 0.041 \\
Role of NFAT in Regulation of the Immune & & \\
Response &
\end{tabular}

C



Figure 5. Developmental pathways are modulated by WSS. (A) Gene expression was determined by Illumina WG-6 BeadChips in E10.5 AGM-derived cells after 6 or $36 \mathrm{~h}$ of culture with WSS or static conditions. The Venn diagram displays overlap of genes differentially expressed between static and WSS at 6 and $36 \mathrm{~h}(n=3$ independent experiments at each time point; unpaired Student's $t$ test: $P<0.01$; twofold threshold). Genes listed in red are up-regulated with application of WSS, whereas genes in blue are down-regulated. (B) Ingenuity pathway analysis reveals roles for WSS in several canonical pathways. (C) Functional themes are identified by network visualization of gene sets enriched by WSS at 6 and $36 \mathrm{~h}$ (p-value cutoff 0.05, FDR 0.8, overlap coefficient cutoff 0.5 ). Each node represents between 10 and 600 genes, where distance between nodes and thickness of edge lines reflects overlap of genes. Direction of enrichment is depicted for $6 \mathrm{~h}$ as color of inner node and for $36 \mathrm{~h}$ as color of node border (up, red; down, blue). cytoplasmic fluorescence (Fig. 6, E and F; andVideos 1 and 2). Although calcium flux was evident in single cells within static cultures, exposure to WSS induced more intense signaling across a greater number of cells. Sequestration of calcium by BAPTAAM reduced WSS-dependent induction of Ptgs 2 transcript (Fig. $6 \mathrm{G}$ ). In static cultures, pharmacological elevation of intracellular calcium concentration by pulse treatment of the calcium ionophore A23187 also stimulated accumulation of COX2 protein (Fig. $6 \mathrm{H}$ ). Observations in ex vivo cultures of AGM were further corroborated by reduction in COX2 protein levels in uncultured $N c x 1^{-/-}$PSp (Fig. 6 I).

\section{WSS activates CREB and the CAMP-PKA signaling axis}

To evaluate the contribution of $\mathrm{PGE}_{2}$ to intracellular signaling, we subjected cells to WSS with or without indomethacin and profiled global gene expression as described above. Analysis of differential gene expression revealed that $\mathrm{PGE}_{2}$ contributed to transcription of CREB targets, as well as core components of Wnt/calcium signaling, including Creb1, Ctbp1, Shc1, Calm2, and Camk1 (Fig. 7 A). In chondrocytes of the bone, WSS was recently shown to promote TOP-luciferase (LEF/TCF reporter) and CRE-luciferase (CREB reporter) activity (Ogawa et al., 2014). Whereas addition of exogenous $\mathrm{PGE}_{2}$ was insufficient to drive activation of TOP-luciferase, $\mathrm{PGE}_{2}$ was capable of promoting activity of the CRE-luciferase reporter. Consistent with these findings, we observed that WSS increased phosphorylation of CREB at serine 133, a posttranslational modification required for CREB-mediated transcription (Fig. 7 B). CREB phosphorylation can be mediated by PKA; thus, the increase in PKA transcript Prkaca by WSS 

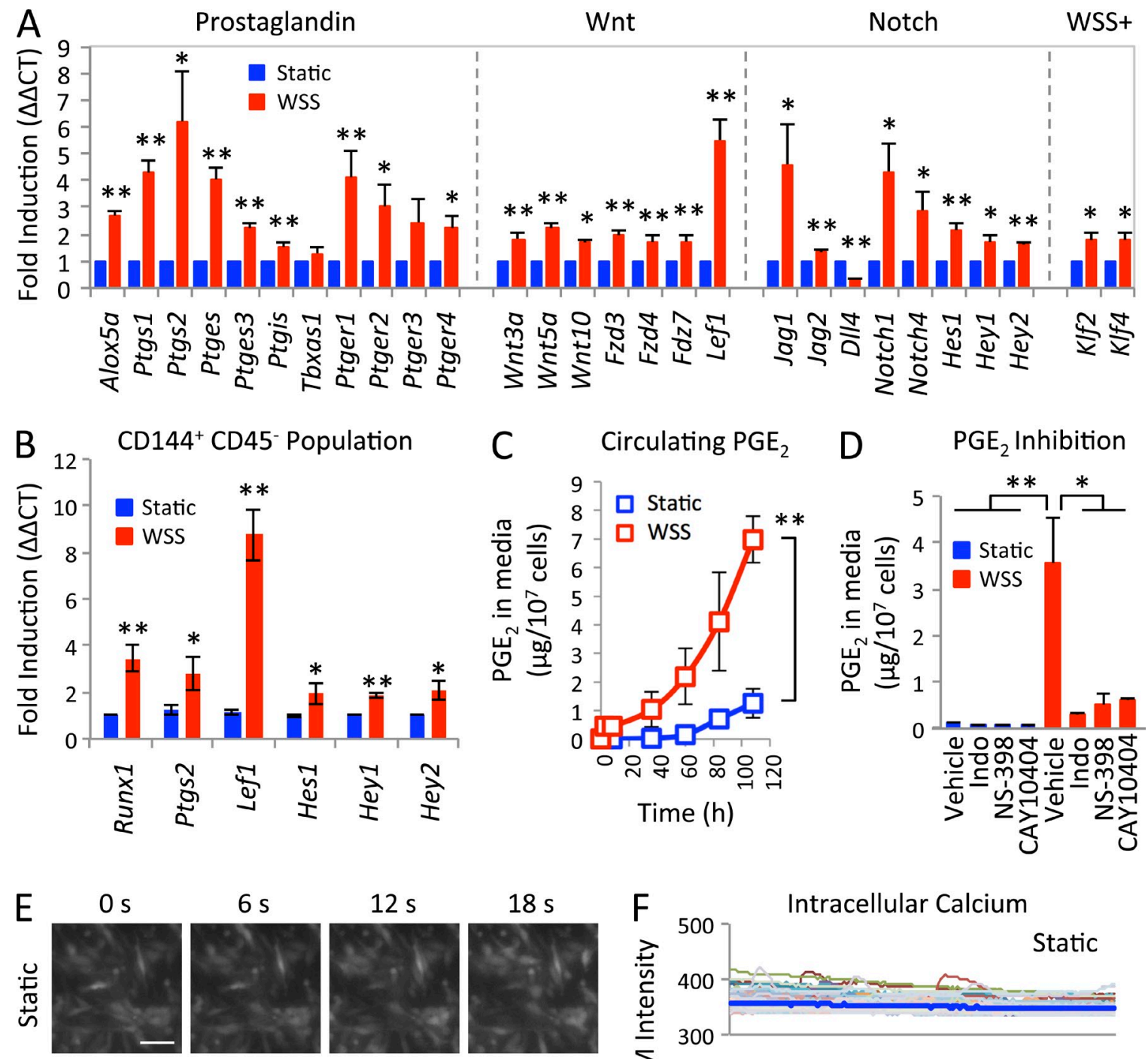

$12 \mathrm{~s}$
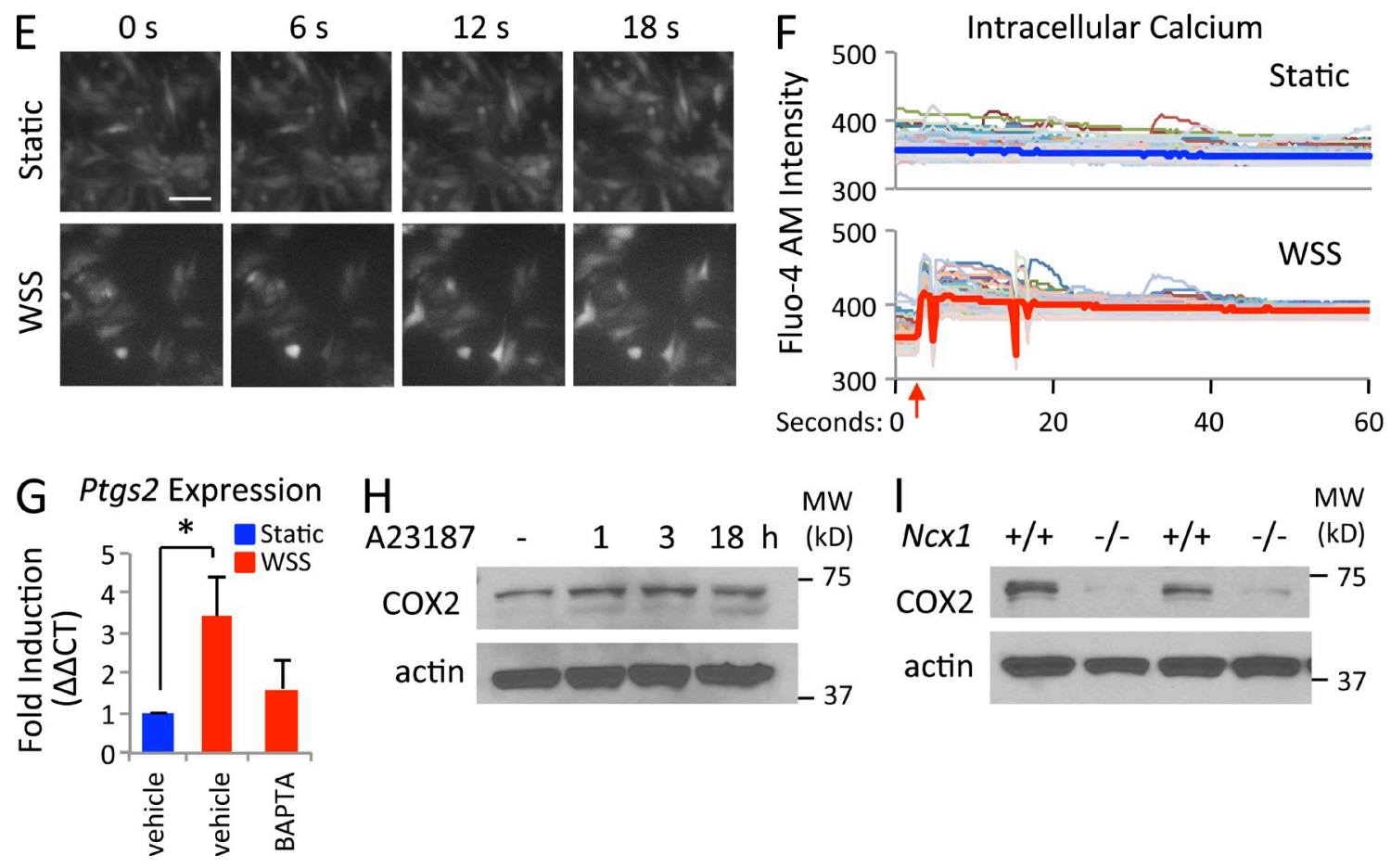

Figure 6. $\mathrm{PGE}_{2}$ production in the AGM is enhanced by calcium flux triggered by WSS. (A) E10.5 AGM-derived cells cultured for $36 \mathrm{~h}$ with WSS activate several pathways required for definitive hematopoiesis ( $n=5$ independent experiments; two-tailed Student's $t$ test or Mann-Whitney rank sum: $\left.{ }^{*}, \mathrm{P}<0.05 ;{ }^{* *}, \mathrm{P}<0.01\right)$. KIf2 and KIf4 are WSS-responsive genes that serve as positive controls for transcriptional activity. (B) Transcriptional up-regulation in WSS-exposed cells is apparent in sorted CD $144^{+}$CD $45^{-}$hemogenic endothelial cells ( $n=5$ independent experiments; unpaired 
at 6 and $36 \mathrm{~h}$ (unpaired Student's $t$ test, $\mathrm{P}=0.016$ [6 h] and $\mathrm{P}=0.004[36 \mathrm{~h}])$ suggested that modulation of PKA downstream of WSS could contribute to enhanced CREB activity. Furthermore, concomitant reduction in Prkaca transcript, the prohematopoietic CREB target Etv2, and P-CREB levels in uncultured $N c \times 1^{-/-}$PSp independently suggested a role for blood flow in coordinating PKA and CREB activity (Figs. $4 \mathrm{C}$ and 7 C). Of six Ncx 1 mutants analyzed in the study, five expressed lower levels of P-CREB relative to wild-type littermates. Total CREB protein was also reduced in four of six mutants, likely indicative of complex signaling inputs known to regulate CREB expression and activity (Shaywitz and Greenberg, 1999). Binding of the $\mathrm{EP}_{2}$ and $\mathrm{EP}_{4}$ receptors by $\mathrm{PGE}_{2}$ stimulates the $\mathrm{G}_{\mathrm{s}}$-adenylyl cyclase pathway, which leads to cAMP production and subsequent PKA activation (Zhang and Daaka, 2011; Yamamizu et al., 2012). As expected, AGM exposed to WSS for $36 \mathrm{~h}$ produced higher levels of intracellular and circulating cAMP compared with static cultures (Fig. 7 A). Importantly, antagonists of COX2 or PKA abolished enhancement in hematopoietic colony forming activity with ex vivo exposure to WSS, as did a blocking antibody to $\mathrm{PGE}_{2}$ (Fig. $7 \mathrm{E}$ ). The adenylyl cyclase agonist forskolin amplified colony-forming potential in WSS-exposed cultures but not static cultures, suggesting that $\mathrm{PGE}_{2}$ cooperates with additional WSS-responsive signaling in initiation of the hematopoietic program. Consistent with this notion, inhibition of COX2 by indomethacin blocks WSS induction not only of CREB and MAPK signaling but also calcium, calmodulin, calcineurin, and NFAT, primary components of noncanonical Wnt/calcium signaling that function to control cell adhesion, migration, and ventral patterning (Fig. $7 \mathrm{~F}$ and Dataset S3; Kohn and Moon, 2005). Based on analyses of BrdU incorporation and Annexin V staining, WSS contributes significantly to survival of the CD $144^{+} \mathrm{CD} 45^{-}$population (Fig. 8). However, $\mathrm{PGE}_{2}$ does not appear to influence cell proliferation or survival, but instead may serve to modulate fate selection through CREB. More detailed analyses of signal transduction will be required to understand the precise nature of how $\mathrm{PGE}_{2}-\mathrm{PKA}$ interfaces with other developmental signaling pathways to modulate hematopoietic-specific gene expression downstream of WSS in the AGM.

\section{$\mathrm{PGE}_{2}$ promotes engraftment of embryonic hematopoietic stem and progenitor cells into adult recipients}

The HSC enhancing ability of $\mathrm{dmPGE}_{2}$ was first identified in pharmacological screens of zebrafish embryos and has since been used for expansion of umbilical cord blood in phase I clinical trials (North et al., 2007; Cutler et al., 2013). To date, the effects of $\mathrm{dmPGE}_{2}$ in mouse and human have only been tested on committed hematopoietic stem and progenitor cells. We therefore evaluated the ability of transient $\mathrm{dmPGE}_{2}$ treatment to promote short- and long-term hematopoietic activity from E10.5 and E11.5 murine AGM. Colony formation assays showed an asymptotic dose-dependent increase in progenitor activity with up to $10 \mu \mathrm{M}$ dmPGE 2 (Fig. 9 A). 2-h $\mathrm{dmPGE}_{2}$ treatment also increased chimerism in the peripheral blood from donor AGM above mean levels in three of five recipients of E10.5 AGM and in six of eight recipients of E11.5 AGM (Fig. 9, B and C). Notably, dmPGE 2 improved $\mathrm{B}$ and $\mathrm{T}$ lymphoid potential of hematopoietic progenitors/stem cells at both embryonic stages, although E11.5 produced the only HSC-like long-term engraftment of all lineages (Fig. 9, $\mathrm{D}$ and E). Collectively, our findings suggest that WSS and $\mathrm{PGE}_{2}$ function together to regulate developmental signaling that determines lineage potential of nascent hematopoietic cells in the earliest stages of definitive hematopoiesis.

\section{DISCUSSION}

Here, we have shown that WSS activates developmental pathways that promote hematopoietic fate and potentiates long-term engraftment of embryonic hematopoietic stem and progenitor cells from the PSp and AGM. Prostaglandin, Wnt, and Notch signaling were all up-regulated in response to WSS. $\mathrm{PGE}_{2}$ production in particular was found to be required for WSS-enhanced progenitor activity, as its stimulatory effects could be inhibited by blocking antibodies or pharmacological inhibition of COX enzyme function. $\mathrm{PGE}_{2}$ was directly responsible for increased cAMP production and contributed to regulation of CREB through PKA. Mimicry of WSS by addition of $\mathrm{dmPGE}_{2}$ induced greater peripheral blood chimerism and enhanced lymphoid potential from E10.5 and E11.5 AGM, supporting a possible mechanism for transduction of mechanical cues into chemical signaling

Student's $t$ test: ${ }^{*}, \mathrm{P}<0.05 ;{ }^{* *}, \mathrm{P}<0.003$ ). (C) Prostaglandin production as measured by $\mathrm{PGE}_{2}$ release into media was increased over time by WSS ( $n=3$ independent experiments; two-way ANOVA: $\left.{ }^{* *}, P=0.001\right)$. (D) PGE biosynthesis was suppressed by addition of indomethacin or COX2-specific antagonists NS-398 and CAY10404. WSS-treated vehicle control produced significantly higher amounts of PGE ${ }_{2}$ than WSS samples treated with COX inhibitors and all static cultured samples at $60 \mathrm{~h}$ of culture ( $n=3$ independent experiments; two-way ANOVA: $\left.{ }^{*}, P<0.02 ;{ }^{* *}, P<0.001\right)$. (E) WSS applied to E11.5 AGM-derived cells triggers elevated levels of intracellular calcium ( $n=3$ independent experiments, $>5$ replicates per experiment). WSS was initiated $3 \mathrm{~s}$ after image acquisition began. Abbreviated videos are available in Videos 1 and 2. Bar, 50 um. (F) Quantification of Fluo-4 AM intensity by MetaMorph captures multiple spikes in calcium flux after application of WSS (red arrow on horizontal axis marks initiation of WSS at 3 s). Pastel traces represent calcium levels in individual cells ( $n=150$ cells), whereas bold traces (blue or red) represent the mean intensity of values collected from individual cells. (G) Ptgs2 transcript level was reduced by an inhibitor of calcium signaling (BAPTA-AM; $n=3$ independent experiments at $3 \mathrm{~h}$ of WSS; one-tailed unpaired Student's $t$ test: ${ }^{*}, \mathrm{P}=0.036 ; \mathrm{P}>0.26$ for comparison between static vehicle- and BAPTA-AM-treated WSS group). (H) COX2 protein accumulates in response to transient treatment with A23187, a compound which increases intracellular calcium. Cells were pulse treated under static conditions with A23187 for 1 or $3 \mathrm{~h}$, washed, and incubated in fresh medium for a total culture period of $18 \mathrm{~h}$. A23187 was not removed from the 18-h sample ( $n=3$ independent experiments at $2 \mu \mathrm{M}$ A23187). (I) COX2 protein levels are decreased in Ncx $1^{-/-}$PSp ( $n=6$ mutant, $n=8$ wild-type littermates analyzed). All data are represented as mean \pm SEM. 
A


$-3.0 \square$
$\square .0$
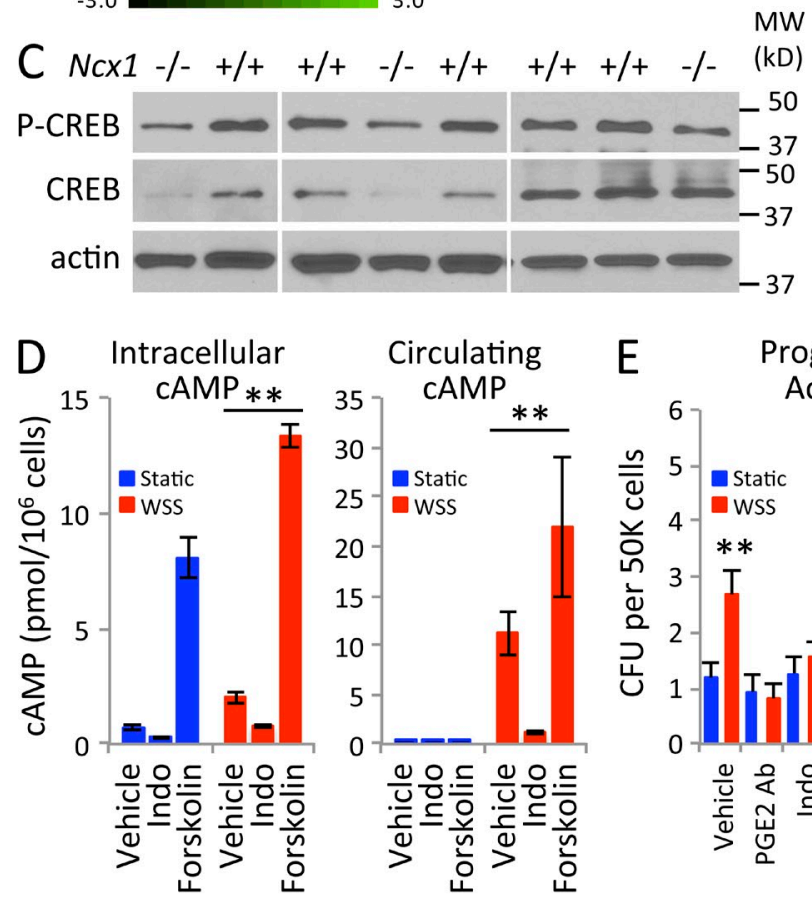

B



Figure 7. WSS stimulates CAMP-PKA signaling and phosphorylation of CREB. (A) Expression of CREB, CAMPPKA, and calmodulin signaling components believed to lie downstream of noncanonical Wnt/calcium signaling are al-

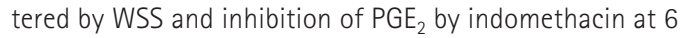
and $36 \mathrm{~h}$ ( $n=3$ independent experiments at each time point). (B) Phosphorylation of ser133 on CREB (P-CREB) is elevated by $3 \mathrm{~h}$ of WSS. (C) P-CREB is reduced in Ncx $1^{-/-}$PSp $(n=6 \mathrm{mu}-$ $\operatorname{tant}, n=8$ wild-type littermates analyzed). Representative data from different gels are separated by white space. (D) Intracellular and circulating (secreted) CAMP is increased by WSS in a $\mathrm{PGE}_{2}$-dependent manner $(n=3$ independent experiments; two-way ANOVA: $\left.{ }^{*}, \mathrm{P}<0.001\right)$. Indomethacin significantly reduced levels of intracellular CAMP (Holm-Šídák comparison: $P=0.009)$ and circulating $C A M P(P=0.005)$. Stimulation of CAMP synthesis by adenylyl cyclase with forskolin serves as a positive control. (E) Blocking antibodies against $\mathrm{PGE}_{2}$ or inhibitors of COX $1 / 2$ effectively suppress WSS-induced progenitor activity in M3434 methylcellulose assays. PKA inhibition by H89 similarly reduces progenitor activity, whereas stimulation of cAMP levels by forskolin elevates hematopoietic activity above static vehicle controls ( $n=3$ independent experiments; two-way ANOVA: $\left.{ }^{* *}, \mathrm{P}<0.001\right)$. (F) Interruption of prostaglandin signaling by indomethacin reduces transcription of Ras/ MAPK/Akt, CREB, and calcineurin/NFAT pathway components related to calcium transport and calmodulin kinase activity (p-value cutoff 0.05, FDR 0.8, overlap coefficient cutoff 0.5). Data are represented as mean \pm SEM.

$\mathrm{F}$

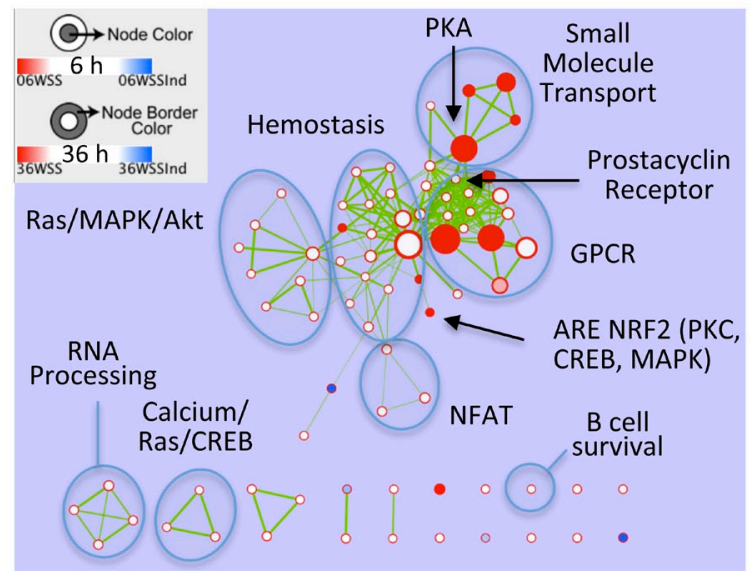

E Progenitor

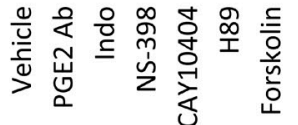



and downstream gene activation within HSCs of the embryonic vasculature.

Prostaglandin signaling has emerged as an attractive target for enhancing hematopoietic function in cell therapy and as a medical countermeasure against radiological and nuclear threats (Goessling et al., 2011; Cutler et al., 2013; Hoggatt et al., 2013c). In animal models and humans, $\mathrm{PGE}_{2}$ has been found to regulate survival, self-renewal, and trafficking of HSCs and progenitors 

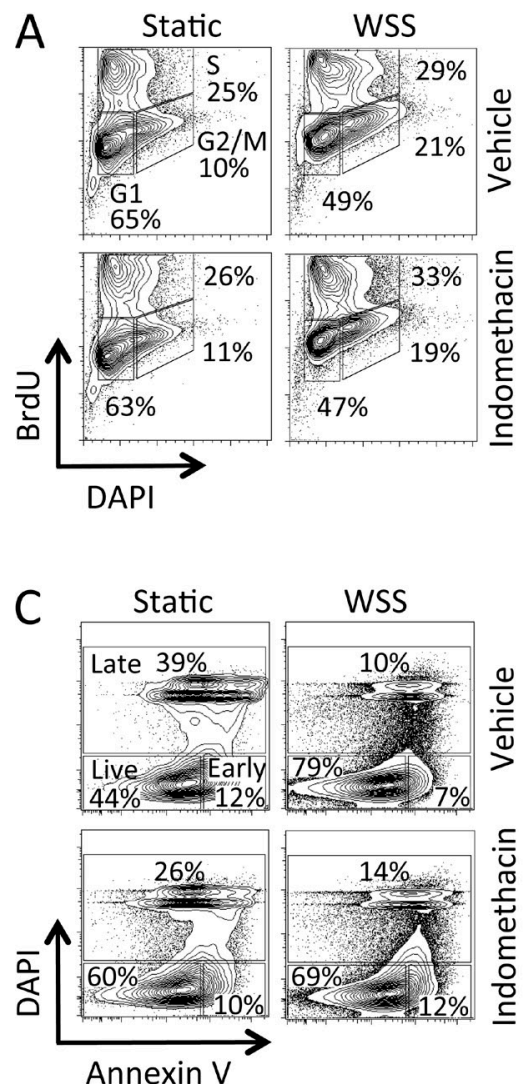
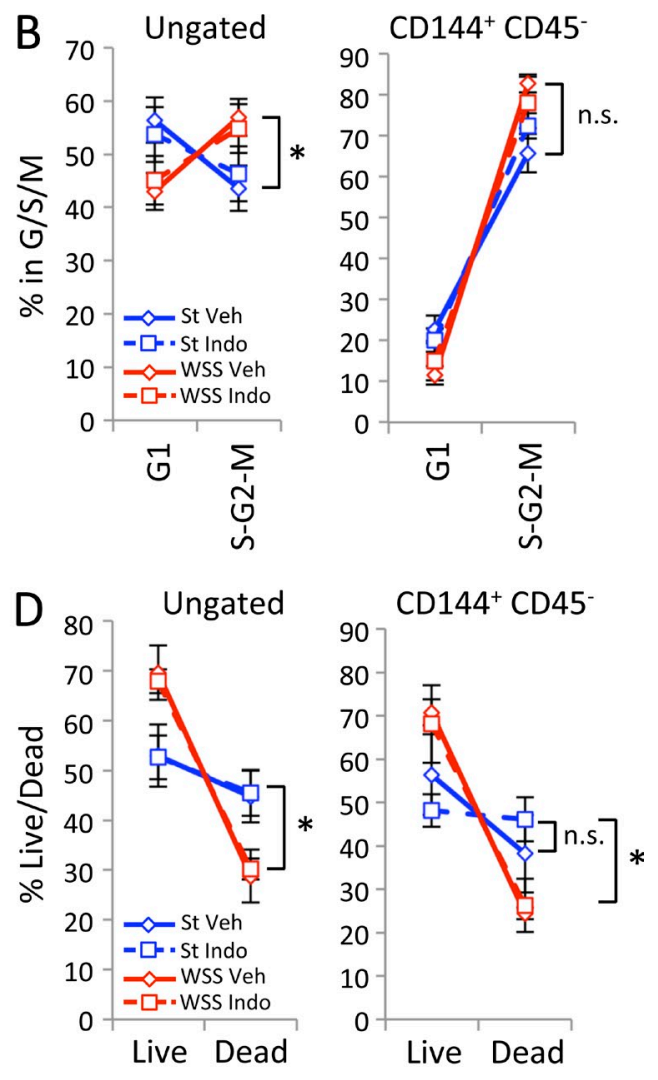

Figure 8. WSS, but not $\mathrm{PGE}_{2}$, contributes to survival and proliferation of cells in the AGM. (A) Representative plots of cell cycle analysis by BrdU incorporation and DNA content analysis. (B) Cellular proliferation is increased in ungated AGM cells cultured with WSS, as measured by total percentage of the population in $S, G 2$, and $M$ phases. No effects on cell cycle are detectable in the CD144+ CD45- population ( $n=3$ independent experiments; two-tailed Student's $t$ test: WSS relative to static, $\left.{ }^{*}, P=0.025\right)$. (C) Events collected from Annexin $V$ binding assays are gated for analysis of cells that are live, undergoing early apoptosis, or are in late stages of apoptosis or necrosis. (D) Analysis of Annexin $V$ staining in the ungated population indicates that $5 \mathrm{dyn} / \mathrm{cm}^{2}$ WSS protects AGM cells from apoptotic cell death ( $n=4$ independent experiments; twotailed Student's $t$ test: WSS relative to static, $\left.{ }^{*}, P=0.049\right)$. Survival of CD144+ CD $45^{-}$endothelial cells is higher in the presence of WSS, and indomethacin has minimal effect on sheared cultures (WSS-indomethacin relative to static-indomethacin, two-tailed Student's $t$ test: $\left.{ }^{*}, P=0.035\right)$. Treatment of static cultures with indomethacin produced moderate but insignificant elevation in nonviable CD144+ CD45- cells (static relative to staticindomethacin, Student's two-tailed $t$ test: $P$ > 0.05). Data are represented as mean \pm SEM.
(Hoggatt et al., 2009, 2013a). Ablation of Ptgs 2 or the terminal prostanoid synthase Ptges results in a variety of hematopoietic defects, impacting macrophages and platelets, and widespread impairment in inflammatory response (Uematsu et al., 2002; Cheng et al., 2006; Yu et al., 2007; Seta et al., 2009). Furthermore, $\mathrm{PGE}_{2}$ has very recently been found to possess morphogen-like effects on bipotential endodermal precursors that determine fate selection between hepatic and pancreatic commitment (Nissim et al., 2014), raising the possibility that $\mathrm{PGE}_{2}$ and downstream PKA activation could direct specification of hematopoietic lineages from precursors of the hemogenic endothelium, perhaps in part through modulation of Wnt signaling.

Our data support a model in which multiple pathways downstream of WSS must converge to balance developmental signaling essential for hematopoiesis. In addition to Wnt and Notch, other pathways altered by WSS corroborate findings from Goessling et al. (2011), in which pulse treatment of human and macaque $\mathrm{CD}_{3} 4^{+}$cells with $\mathrm{dmPGE}_{2}$ induced pathways such as PKA, NFAT, and ERK/MAPK. Mechanosensation in hemogenic endothelium and other cells of the AGM involves release of second messengers into the cytosol, including intracellular calcium, that directly stimulate enzyme functions required for prostaglandin synthesis. In osteocytes, calcium flux triggers rapid $\mathrm{PGE}_{2}$ synthesis and secretion through a biochemical cascade that includes PLC, DAG, PKC, and PLA (Ajubi et al., 1999). Prostaglandin production has also been found in osteoblasts to be dependent on focal adhesions and transcriptional transactivation of Ptgs 2 by transcription factors, including C/EBP $\beta, A P-1$, and CREB (Ogasawara et al., 2001; Ponik and Pavalko, 2004; Rangaswami et al., 2012). Prostaglandin synthesis is elevated in CD $144^{+}$CD $45^{-}$hemogenic endothelial cells, but $\mathrm{PGE}_{2}$ signaling could also originate from other cell types in the AGM, such as committed CD $144^{+/-}$ckit $^{+}$hematopoietic progenitors (unpublished data). As $\mathrm{PGE}_{2}$ is released into the aortic lumen, activation of $\mathrm{EP}_{2}$ / $\mathrm{EP}_{4}$ receptors expressed on hemogenic endothelium or committed hematopoietic stem and progenitor cells stimulates $G$ protein-dependent adenylyl cyclase activity and elevates intracellular cAMP levels. PKA, in the presence of cAMP, can then modulate CREB-dependent gene expression. Interestingly, genetic ablation of CREB phenocopies Wnt1 and Wnt3a knockout in differentiating myoblasts, suggesting that activation of CREB by PKA is a prerequisite for transduction of some noncanonical Wnt signals (Chen et al., 2005). We find that WSS stimulates CREB phosphorylation and up-regulates core components of noncanonical Wnt signaling, including calmodulin, calcineurin, NFAT, and calmodulin-dependent kinase, which are known to play an important role in selfrenewal and repopulating activity of adult HSCs (Nemeth et al., 2007; Sugimura et al., 2012). Wnt receptor and ligand transcript levels were statistically unchanged by indomethacin or the PKA antagonist H89, suggesting that Wnt machinery at the cell membrane is regulated independently of $\mathrm{PGE}_{2}$ but 

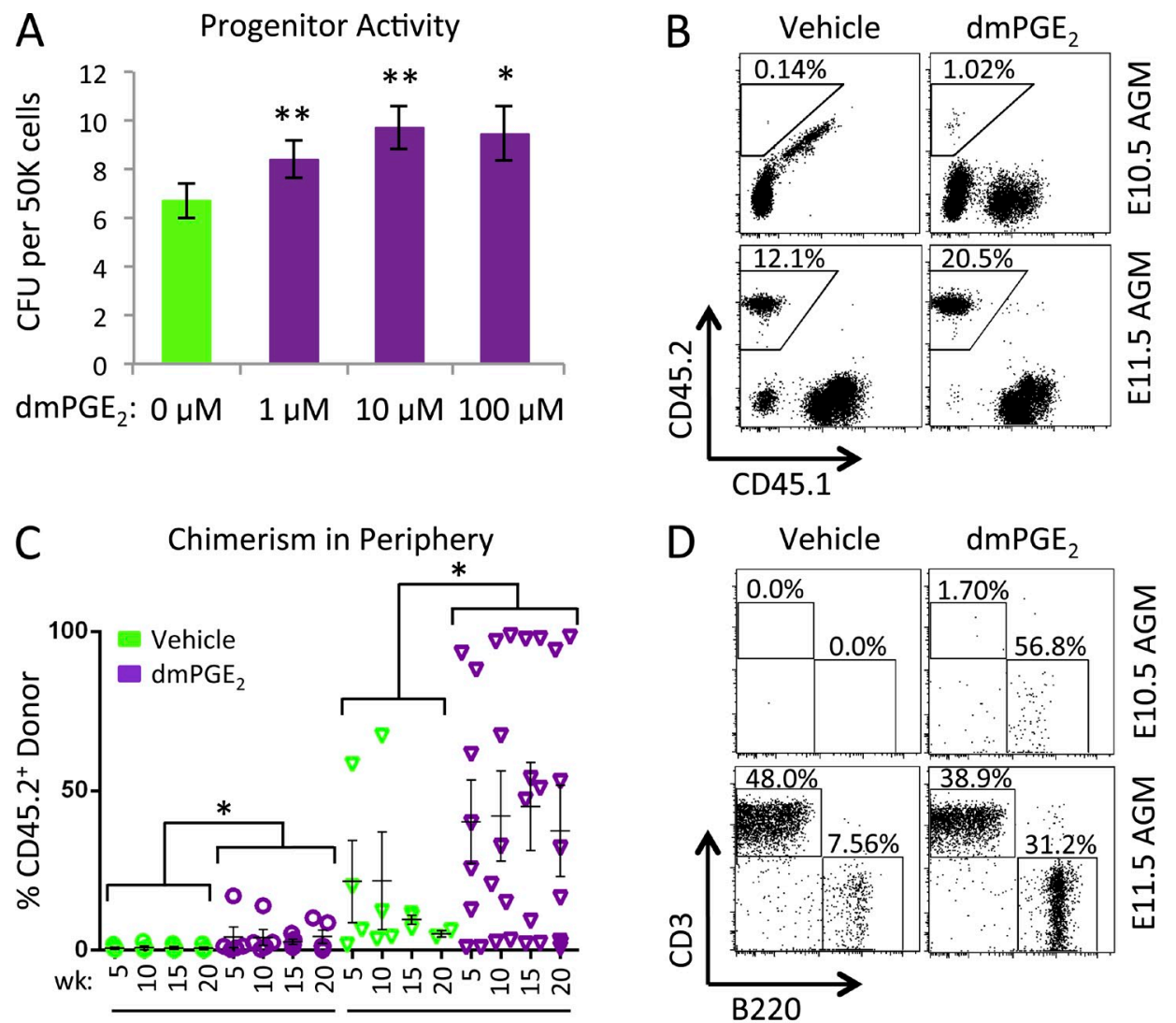

E10.5

E11.5

$E$

Donor Lineages in Periphery

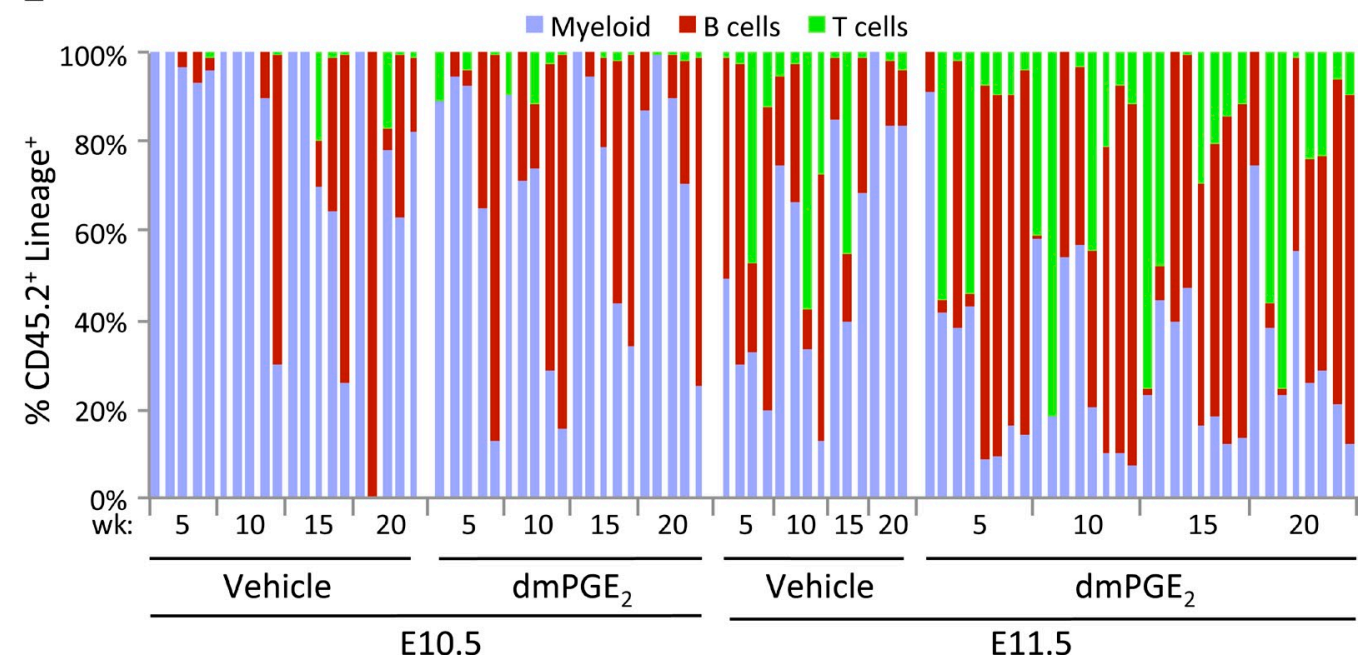

Figure 9. $\mathrm{dmPGE}_{2}$ expands short- and long-term hematopoietic activity of the AGM. (A) Colony-forming unit activity was increased by a transient 2-h exposure to dmPGE 2 at $37^{\circ} \mathrm{C}\left(n=3\right.$ independent experiments; paired Student's $t$ test: $\left.{ }^{*}, \mathrm{P}=0.01 i^{* *}, \mathrm{P}<0.01\right)$. (B) Representative plots show CD45.2 ${ }^{+}$ donor contribution to peripheral blood at $10 \mathrm{wk}$ after transplantation. (C) dmPGE 2 potentiated long-term, multilineage engraftment of definitive hematopoietic cells from AGM at E11.5 (2 e.e.) and, to a lesser extent, E10.5 (4 e.e.; $n=5$ E10.5 vehicle, $n=5$ E10.5 dmPGE,$n=4$ E11.5 vehicle, $n=8$ E11.5 dmPGE; two-way ANOVA: $\left.{ }^{*}, \mathrm{P}<0.04\right)$. (D) Plots show T cell $\left(\mathrm{CD}^{+}\right)$and B cell $\left(\mathrm{B} 220^{+}\right)$lymphoid contribution from E10.5 and E11.5 AGM recipients shown in B. (E) Lineages present in CD $45.2^{+}$donor peripheral blood from individual recipients at 5, 10, 15, and 20 wk after transplantation. Data are represented as mean \pm SEM.

that target gene activation may be regulated by WSS-induced phosphorylation of CREB (unpublished data). The nature of the relationship between $\mathrm{PGE}_{2}$ and NFAT will require further investigation, though it appears that $\mathrm{PGE}_{2}$ may contribute to signaling activity through calcium, calmodulin, calmodulindependent kinase, and NFAT. CREB and NFAT are essential 
for transduction of noncanonical Wnt signals; thus, regulation of the activity of these transcription factors may allow $\mathrm{PGE}_{2}$ to "fine tune" the dosage of canonical Wnt signaling required for expansion and maintenance of HSCs (Luis et al., 2011).

The identification of biomechanical cues that support hematopoiesis has begun to redefine our understanding of the types of signals that comprise the hematopoietic niche. Data from the current study demonstrate that $\mathrm{PGE}_{2}$ contributes essential signaling downstream of WSS to govern the expansion of hematopoietic populations with long-term reconstitution potential in the developing embryo. Moreover, we find that WSS-induced $\mathrm{PGE}_{2}$ acts through calcium and cAMPPKA to regulate CREB for induction of prohematopoietic developmental programs. Further studies will be required to precisely address how biomechanical forces coordinate these and other signaling pathways in the PSp and AGM to define hematopoietic potential.

\section{MATERIALS AND METHODS}

Mice. Timed pregnancies were bred in house to E9.5-11.5 (C57BL/6J or Ncx1) or were purchased as pregnant females from Taconic at E9.5 for largescale shearing experiments (Swiss Webster). Gestational age of embryos was determined by observation of a copulation plug on E0.5 and number of somite

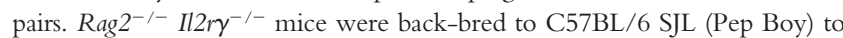

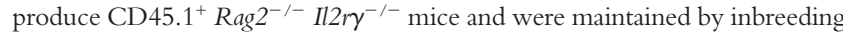

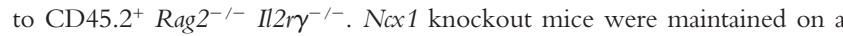
C57BL/6J background (minimum ninth generation). All animal experiments were performed according to the University of Texas Medical School at Houston and Children's Hospital Boston guidelines for laboratory animals.

Culture of PSp- and AGM-derived cells. Embryos from C57BL/6J or Swiss Webster timed pregnancies were microdissected for isolation of E9.5 PSp or E10.5 AGM regions. Tissues were dissociated either by treatment with Accutase (STEMCELL Technologies) at room temperature with gentle agitation for $20 \mathrm{~min}$ or, for WSS transplantation experiments, by $0.1 \%$ dispase (Gibco) at $37^{\circ} \mathrm{C}$ for $30 \mathrm{~min}$. Cells were then resuspended in M5300 MyeloCult medium (STEMCELL Technologies) enriched with Hepes (Invitrogen; $12.5 \mathrm{ml}$ of $1 \mathrm{M}$ Hepes per $500 \mathrm{ml}$ MyeloCult medium), nonessential amino acids (Gibco), sodium pyruvate (Gibco), $10 \mathrm{U} / \mathrm{ml}$ penicillin (Lonza), and $10 \mu \mathrm{g} / \mathrm{ml}$ streptomycin (Lonza) without addition of hydrocortisone. Cells were plated on tissue culture plastic coated with a 1:20 MatrigelPBS solution (BD) at a concentration of 8 e.e. per $10 \mathrm{~cm}^{2}$ in preparation for culture on a dynamic flow system (Adamo et al., 2009) or in microfluidics (Li et al., 2014), as described previously. Microfluidics consisted of IBIDI VI ${ }^{0.4}$ channel slides in line with a recirculating medium system driven by a single Harvard Apparatus PHD ULTRA 4400 with remote syringe pump, 0.27 PSI crack pressure check valves (Qosina), and female luer lock three-way stop cocks (Qosina). After $6.5 \mathrm{~h}$ of incubation, nonadherent cells were washed away and cells were cultured in enriched MyeloCult medium with $10 \mathrm{ng} / \mathrm{ml}$ murine SCF (PeproTech) in static/low-flow conditions $\left(<0.0001 \mathrm{dyn} / \mathrm{cm}^{2}\right)$ or in the presence of WSS $\left(5 \mathrm{dyn} / \mathrm{cm}^{2}\right)$. The shear stress pattern used to induce hematopoiesis is described in our previous work (Adamo et al., 2009). At the end of the culture period, adherent and nonadherent cells were collected by a 5 -min incubation in Accutase, washed, resuspended in MyeloCult, and transferred to functional or phenotypic assays. Cells analyzed immediately by flow cytometry were immunostained with antibodies available through $\mathrm{BD}$, purified rat CD144 and APC c-kit (CD117); eBioscience, APC-Cy7 CD45.2; and Invitrogen, Alexa Fluor 488 anti-rat IgG. Colony formation assays were established in M3434 MethoCult medium (STEMCELL Technologies) at 100,000 cells per $1.5 \mathrm{ml}$ media and counted after 10-14 d.

Modulation of calcium and $\mathrm{PGE}_{2}-\mathrm{PKA}$ signaling. Cells were cultured with pharmacological compounds or antibodies to block $\mathrm{PGE}_{2}$ production and/or signaling by incubation with $10 \mu \mathrm{M}$ indomethacin, $10 \mu \mathrm{M}$ NS-398, $1 \mu \mathrm{M}$ CAY10404 (Cayman Chemical), or 1:1,000 anti-PGE 2 antibodies (Abcam) for the duration of culture with or without WSS. H89 (Cayman Chemical) was applied at $10 \mu \mathrm{M}$ to inhibit PKA activity. Forskolin (SigmaAldrich) was administered at $10 \mu \mathrm{M}$ as an adenylyl cyclase activator to stimulate cAMP production. The stabilized synthetic analogue $\mathrm{dmPGE}_{2}$ (Cayman Chemical) was applied to freshly dissociated AGM cells for $2 \mathrm{~h}$ at $37^{\circ} \mathrm{C}$ from 1 to $100 \mu \mathrm{M}$ for colony formation assays or at $10 \mu \mathrm{M}$ for transplantation into adult recipient mice. Intracellular calcium was sequestered by $10 \mu \mathrm{M}$ BAPTA-AM (Tocris Bioscience) and elevated by $2 \mu \mathrm{M}$ of calcium ionophore A23187 (Tocris Bioscience).

Gene expression profiling. Total RNA was extracted with QIAGEN RNeasy kits for analysis of gene expression by Illumina Mouse WG-6 v2.0 Expression BeadChips or by TaqMan Assays. RT of RNA for qRT-PCR was performed using Multiscribe DNA polymerase (Applied Biosystems), and PCR was performed in 10- $\mu$ l reactions on a 7500 Real-Time PCR System (Applied Biosystems). All procedures were conducted according to the manufacturer's instructions. Illumina data were checked for quality, background corrected, and quantile normalized with GenomeStudio (Illumina). Analysis of differential expression was conducted with GenomeStudio for probe sets filtered by spot detection $(\mathrm{P}<0.01)$ and difference in mean signal intensity between treatment groups (dif $>20$ ). Significantly changed genes were subjected to analysis of canonical pathways curated by Ingenuity (IPA, Ingenuity Systems). Gene set expression analysis (GSEA) was conducted with unfiltered genes using curated gene lists downloaded from MSigDB. Ranked gene list data were imported into Cytoscape for visualization of functional enrichments with Enrichment Map using edge-weighted forcedirected layout. Heat maps were generated using genes selected from differential gene expression analysis in GenePattern. Expression data have been deposited for public access in the NCBI Gene Expression Omnibus (GEO) under accession no. GSE62463.

Measurements of $\mathbf{P G E}_{2}$ and cAMP. E10.5 AGM were dissociated and exposed to WSS or static culture conditions for up to $110 \mathrm{~h}$. Cell lysates and/or medium was processed for measurement with the Prostaglandin $E_{2}$ Express EIA kit (Cayman Chemical) or the Direct cAMP ELISA kit (Enzo Life Sciences). Standard curves were established in parallel for quantification of sample concentrations.

Transplantation. Microdissected PSp from 64 E9.5 embryos for WSS experiments were pooled and dissociated in $0.1 \%$ dispase-PBS with calcium and magnesium. PSp cells were cultured as described above and prepared for transplantation by gentle dissociation with $0.1 \%$ dispase at $37^{\circ} \mathrm{C}$ for $20 \mathrm{~min}$. $\mathrm{CD} 45.1^{+}$or CD $45.1^{+} \mathrm{CD} 45.2^{+}$Rag $2^{-/-} I l 2 r \gamma^{-/-}$recipient mice were lethally irradiated with a split dose of 9.25 Gy (separated by 3 h) just before transplantation. Each primary recipient received 16 e.e. of E9.5 PSp-derived cells plus 500,000 CD $45.1^{+} \mathrm{CD} 45.2^{+} \mathrm{Rag}^{-/-} \mathrm{Il} 2 \mathrm{r} \mathrm{\gamma}^{-/-}$whole bone marrow competitor cells. Secondary recipients received $20,000 \mathrm{CD} 45.2^{+}$cells after sorting from primary recipient bone marrow and 200,000 adult competitor marrow cells.

For transplantation of $\mathrm{dmPGE}_{2}$-treated AGM cells, embryos were microdissected, dissociated at room temperature with Accutase, resuspended in $10 \mu \mathrm{M} \mathrm{dmPGE}{ }_{2}$-containing MyeloCult media, and incubated at $37^{\circ} \mathrm{C}$ for $2 \mathrm{~h}$. Cells were then washed in PBS without calcium and magnesium, filtered through a cell strainer, and injected retroorbitally into adult $\mathrm{CD} 45.1^{+}$or $\mathrm{CD} 45.1^{+} \mathrm{CD} 45.2^{+} \mathrm{Rag}^{-/-} \mathrm{Il} 2 \mathrm{rr}^{-/-}$recipients. Each recipient of $\mathrm{dmPGE}_{2^{-}}$ treated cells received a split dose of 8.25 Gy irradiation (separated by $3 \mathrm{~h}$ ), no competitor, and 4 e.e. of E10.5 AGM or 2 e.e. of E11.5 AGM.

Peripheral blood and bone marrow analysis. Peripheral blood was collected at 4, 6, 10, and $20 \mathrm{wk}$ after transplantation. Red blood cells were removed by $1 \%$ dextran sulfate-PBS-EDTA separation and treatment with RBC lysing buffer (Sigma-Aldrich). Leukocytes were immunostained for discrimination of CD 45 allelic variants and detection of lineage markers, followed by analysis on a five-laser BD LSR II flow cytometer. Antibodies used from BD 
included FITC CD45.1, biotin CD8a, biotin CD4, biotin CD3e, APC CD45.2, PE-Cy7 IgM, APC-Cy7 CD45R/B220, and PE Ly-6G/Ly-6C (Gr-1). We also used Pacific Blue CD11b (BioLegend), PE-Cy5 CD19 (eBioscience), Pacific Orange streptavidin (Invitrogen), and DAPI for live-dead discrimination (Sigma-Aldrich). Engraftment was measured as the percentage of CD45.2 cells within the $\mathrm{CD} 45^{+}$population. Peripheral blood from untransplanted CD45.1 $1^{+} \mathrm{CD} 45.2^{+} \operatorname{Rag} 2^{-/-} \mathrm{Il} 2 \mathrm{r} \gamma^{-/-}$mice was used to evaluate background in the CD45.2 gate.

Bone marrow was collected at 20-wk after transplantation for analysis of chimerism and B lineage maturation. In brief, bones were crushed in PBS with a mortar and pestle and filtered through a $70-\mu \mathrm{m}$ cell strainer. The resulting cell suspension was subjected to RBC lysis and incubation with antibodies from BD: APC-Cy7 CD45.1, APC CD45.2, PE-Cy5 CD45R/B220, FITC CD24, PE CD25, PE-Cy7 IgM, biotin CD43, and Pacific Blue streptavidin. Cells were sorted and analyzed on a 5-laser BD Aria II special sorter. Limiting numbers of CD $45.2^{+}$cells were subsequently transferred to lethally irradiated secondary recipients for further evaluation of long-term reconstitution potential, as described in the transplantation section above.

Immunoblotting. Cells were harvested in RIPA buffer $(150 \mathrm{mM}$ sodium chloride, $1 \%$ Triton X-100, 1\% sodium deoxycholate, $0.1 \%$ SDS, $50 \mathrm{mM}$ Tris- $\mathrm{HCl}, \mathrm{pH} 7.5$, and $2 \mathrm{mM}$ EDTA) with $1 \%$ protease and phosphatase inhibitor cocktails (Sigma-Aldrich). Equal amounts of protein were separated by SDS-PAGE and analyzed by immunoblotting with standard procedures. Antibodies used for immunodetection included COX2 (Abcam), phosphoCREB (Ser133; Cell Signaling Technology), CREB (Cell Signaling Technology), and $\beta$-actin (Santa Cruz Biotechnology, Inc.). Gel images were scanned and the density of the protein bands was quantified as a ratio to the actin loading control by MCID Analysis 7.1 software (Imaging Research).

Calcium imaging. Dissociated E11.5 AGM cells were plated at lower density $\left(120,000 \mathrm{cells} / \mathrm{cm}^{2}\right)$ for discrimination of calcium sparks in individual cells. In brief, adherent cells were washed with isotonic Tyrode's solution $(139 \mathrm{mM} \mathrm{NaCl}, 3 \mathrm{mM} \mathrm{KCl}, 17 \mathrm{mM} \mathrm{NaHCO}$, $12 \mathrm{mM}$ D-glucose, $3 \mathrm{mM}$ $\mathrm{CaCl}_{2}$, and $1 \mathrm{mM} \mathrm{MgCl}$ ) and incubated with the fluorescent calcium indicator $5 \mu \mathrm{M}$ Fluo-4 AM (F14201; Invitrogen) in isotonic Tyrode's solution for $5 \mathrm{~min}$ at $37^{\circ} \mathrm{C}$. Fresh MyeloCult medium was applied, and cells were placed in an environmental chamber maintained at $37^{\circ} \mathrm{C}, 5 \% \mathrm{CO}_{2}$ for imaging. Successive images were collected at a 300-ms time interval for $60 \mathrm{~s} \mathrm{(201}$ images total) using MetaMorph v7.7.9.0 on an Olympus IX81 fluorescent microscope equipped with an Andor iXon X3 885 EMCCD camera. WSS was applied $3 \mathrm{~s}$ after initiation of image acquisition and thus represents static culture at start time. Images were subsequently analyzed for integrated intensity using manual selection of individual cell boundaries with MetaMorph software. Videos were compiled using ImageJ 1.46r software (National Institutes of Health) using 10 frames per second for visualization.

Assessment of cell death by Annexin V staining. E10.5 AGM were dissociated and exposed to WSS or control culture conditions for $36 \mathrm{~h}$. After the culture period, adherent and nonadherent cells were collected with Accutase and washed in MyeloCult media. Cells were immunostained on ice with each antibody in $2 \%$ FBS-PBS for 20 min, first with rat anti-mouse VE-Cadherin (BD) antibody and then with Alexa Fluor 488 anti-rat IgG (Invitrogen). Cells were washed and additional cell surface markers were detected with APC c-kit (CD117; BD) and APC-Cy7 CD45.2 (eBioscience) Annexin $\mathrm{V}$ binding buffer was used for subsequent washes and for incubation with PE-Cy7 Annexin V (eBioscience) at room temperature for $15 \mathrm{~min}$. Cells were resuspended in binding buffer containing $1 \mu \mathrm{g} / \mathrm{ml}$ DAPI before analysis on a three-laser LSR II flow cytometer.

Measurement of proliferation by BrdU incorporation. BrdU was added to a final concentration of $10 \mu \mathrm{M}$ after culture for $34 \mathrm{~h}$ under WSS or static conditions. WSS or static culture was maintained for an additional $2 \mathrm{~h}$, and then cells were washed in PBS and recovered by Accutase treatment. Cells were incubated sequentially in $2 \%$ FBS-PBS for 20 min with rat anti-mouse VE-Cadherin, Alexa Fluor 488 anti-rat IgG, and APC-Cy7 CD45.2. Cells were then fixed and stained according to the manufacturer's instructions for the BD BrdU Flow kit. In brief, cells were fixed on ice for $15 \mathrm{~min}$ in Cytofix/Cytoperm buffer, washed in Perm/Wash buffer, and incubated for $10 \mathrm{~min}$ on ice in Cytoperm Permeabilization buffer. Cells were fixed again in Cytofix/Cytoperm buffer and subsequently treated with $300 \mu \mathrm{g} / \mathrm{ml}$ DNase for $1 \mathrm{~h}$ at $37^{\circ} \mathrm{C}$. Cells were then stained in Perm/Wash buffer containing APC anti-BrdU antibody at room temperature for $20 \mathrm{~min}$ and resuspended in $10 \mu \mathrm{g} / \mathrm{ml}$ DAPI solution for analysis on an LSR II flow cytometer.

Statistical analyses. All data were analyzed with SigmaPlot 12.5 for statistical significance and are reported as mean \pm SEM. Differences in gene expression, cell surface labeling, and colony formation were analyzed with the unpaired Student's $t$ test or with the Mann-Whitney Rank Sum test where assumptions of normality and homoscedasticity were not met. Two-way ANOVA and the Holm-Š́dák method for multiple comparisons were used to evaluate differences in peripheral blood chimerism over time, drug effects on colony formation, and changes in levels of $\mathrm{PGE}_{2}$ and cAMP. Significance levels of $\mathrm{P}<0.05$ and $\mathrm{P}<0.01$ are denoted in graphs by a single asterisk (*) or double asterisks $(* *)$, respectively. Representative results from at least three independent biological replicates are shown unless stated otherwise.

Online supplemental material. Videos 1 and 2 show calcium imaging in live cell cultures. Dataset S1, included as a separate Excel file, contains differential gene expression analysis. Datasets S2 and S3, included as separate Excel files, include lists of gene sets within functional clusters of enrichment analysis between static and WSS or WSS vehicle- and WSS indomethacintreated AGM cells, respectively. Online supplemental material is available at http://www.jem.org/cgi/content/full/jem.20142235/DC1.

We thank Drs. S. McKinney-Freeman, C. Dessauer, G. Heffner, A.-L. Tsai, P. Kim, and D. Shah for critical discussions and S. Lazo-Kallanian, A. Hazen, and R. Mathieu for flow cytometry.

This work was funded by grants from the American Society of Hematology (to P.L. Wenzel), State of Texas Emerging Technology Fund (to P.L. Wenzel), and National Institutes of Health (to P.L. Wenzel, G.Q. Daley, and G. Garcia-Cardeña). L. Adamo was partially funded by the Giovanni Armenise-Harvard Foundation. G.Q. Daley is an Investigator of the Howard Hughes Medical Institute.

The authors declare no competing financial interests.

Author contributions: M.F. Diaz, N. Li, H.J. Lee, L. Adamo, S.M. Evans, H.E. Willey, N. Arora, Y.-s. Torisawa, D.A. Vickers, O. Naveiras, and S.A. Murthy designed and performed experiments and analyzed the data. D.E. Ingber and S.A. Morris provided guidance on microfluidic WSS systems. G.Q. Daley and G. Garcia-Cardeña conceived the study, directed the research, and revised the manuscript. P.L. Wenzel designed the study, performed experiments, analyzed the data, wrote the manuscript, and directed the research.

Submitted: 1 December 2014

Accepted: 17 March 2015

\section{REFERENCES}

Adamo, L., O. Naveiras, P.L. Wenzel, S. McKinney-Freeman, P.J. Mack, J. Gracia-Sancho, A. Suchy-Dicey, M. Yoshimoto, M.W. Lensch, M.C. Yoder, et al. 2009. Biomechanical forces promote embryonic haematopoiesis. Nature. 459:1131-1135. http://dx.doi.org/10.1038/nature08073

Ajubi, N.E., J. Klein-Nulend, M.J. Alblas, E.H. Burger, and P.J. Nijweide. 1999. Signal transduction pathways involved in fluid flow-induced PGE2 production by cultured osteocytes. Am. J. Physiol. 276:E171-E178.

Alshihabi,S.N.,Y.S. Chang,J.A. Frangos, and J.M.Tarbell. 1996. Shear stress-induced release of $\mathrm{PGE}_{2}$ and $\mathrm{PGI}_{2}$ by vascular smooth muscle cells. Biochem. Biophys. Res. Commun. 224:808-814. http://dx.doi.org/10.1006/bbrc.1996.1104

Chen, A.E., D.D. Ginty, and C.M. Fan. 2005. Protein kinase A signalling via CREB controls myogenesis induced by Wnt proteins. Nature. 433:317-322. http://dx.doi.org/10.1038/nature03126

Cheng, Y., M. Wang, Y. Yu, J. Lawson, C.D. Funk, and G.A. Fitzgerald. 2006. Cyclooxygenases, microsomal prostaglandin E synthase-1, and 
cardiovascular function. J. Clin. Invest. 116:1391-1399. http://dx.doi .org/10.1172/JCI27540

Cumano, A., J.C. Ferraz, M. Klaine, J.P. Di Santo, and I. Godin. 2001. Intraembryonic, but not yolk sac hematopoietic precursors, isolated before circulation, provide long-term multilineage reconstitution. Immunity. 15: 477-485. http://dx.doi.org/10.1016/S1074-7613(01)00190-X

Cutler, C., P. Multani, D. Robbins, H.T. Kim, T. Le, J. Hoggatt, L.M. Pelus, C. Desponts,Y.B. Chen, B. Rezner, et al. 2013. Prostaglandin-modulated umbilical cord blood hematopoietic stem cell transplantation. Blood.122: 3074-3081. http://dx.doi.org/10.1182/blood-2013-05-503177

Dzierzak, E., and N.A. Speck. 2008. Of lineage and legacy: the development of mammalian hematopoietic stem cells. Nat. Immunol. 9:129-136. http://dx.doi.org/10.1038/ni1560

Eilken, H.M., S. Nishikawa, and T. Schroeder. 2009. Continuous single-cell imaging of blood generation from haemogenic endothelium. Nature. 457:896-900. http://dx.doi.org/10.1038/nature07760

Frangos, J.A., S.G. Eskin, L.V. McIntire, and C.L. Ives. 1985. Flow effects on prostacyclin production by cultured human endothelial cells. Science. 227:1477-1479. http://dx.doi.org/10.1126/science.3883488

Godin, I.E., J.A. Garcia-Porrero, A. Coutinho, F. Dieterlen-Lièvre, and M.A. Marcos. 1993. Para-aortic splanchnopleura from early mouse embryos contains B1a cell progenitors. Nature. 364:67-70. http://dx.doi .org/10.1038/364067a0

Goessling, W., T.E. North, S. Loewer, A.M. Lord, S. Lee, C.L. StoickCooper, G. Weidinger, M. Puder, G.Q. Daley, R.T. Moon, and L.I. Zon. 2009. Genetic interaction of PGE2 and Wnt signaling regulates developmental specification of stem cells and regeneration. Cell. 136:1136-1147. http://dx.doi.org/10.1016/j.cell.2009.01.015

Goessling, W., R.S. Allen, X. Guan, P. Jin, N. Uchida, M. Dovey, J.M. Harris, M.E. Metzger, A.C. Bonifacino, D. Stroncek, et al. 2011. Prostaglandin E2 enhances human cord blood stem cell xenotransplants and shows long-term safety in preclinical nonhuman primate transplant models. Cell Stem Cell. 8:445-458.http://dx.doi.org/10.1016/j.stem.2011.02 .003

Gordon-Keylock, S., M. Sobiesiak, S. Rybtsov, K. Moore, and A. Medvinsky. 2013. Mouse extraembryonic arterial vessels harbor precursors capable of maturing into definitive HSCs. Blood. 122:2338-2345. http://dx.doi.org/10.1182/blood-2012-12-470971

Hardy, R.R., and K. Hayakawa. 1991. A developmental switch in B lymphopoiesis. Proc. Natl. Acad. Sci. USA. 88:11550-11554. http://dx.doi .org/10.1073/pnas.88.24.11550

Hoggatt, J., P. Singh, J. Sampath, and L.M. Pelus. 2009. Prostaglandin $\mathrm{E}_{2}$ enhances hematopoietic stem cell homing, survival, and proliferation. Blood. 113:5444-5455. http://dx.doi.org/10.1182/blood-2009-01-201335

Hoggatt, J., K.S. Mohammad, P. Singh, A.F. Hoggatt, B.R. Chitteti, J.M. Speth, P. Hu, B.A. Poteat, K.N. Stilger, F. Ferraro, et al. 2013a. Differential stem- and progenitor-cell trafficking by prostaglandin $\mathrm{E}_{2}$. Nature. 495:365-369. http://dx.doi.org/10.1038/nature11929

Hoggatt, J., K.S. Mohammad, P. Singh, and L.M. Pelus. 2013b. Prostaglandin $\mathrm{E}_{2}$ enhances long-term repopulation but does not permanently alter inherent stem cell competitiveness. Blood. 122:2997-3000. http://dx.doi .org/10.1182/blood-2013-07-515288

Hoggatt, J., P. Singh, K.N. Stilger, P.A. Plett, C.H. Sampson, H.L. Chua, C.M. Orschell, and L.M. Pelus. 2013c. Recovery from hematopoietic injury by modulating prostaglandin $\mathrm{E}_{2}$ signaling post-irradiation. Blood Cells Mol. Dis. 50:147-153. http://dx.doi.org/10.1016/j.bcmd.2012.11.006

Iida,A., K. Sakaguchi, K. Sato, H. Sakurai, D. Nishimura,A. Iwaki, M. Takeuchi, M. Kobayashi, K. Misaki, S. Yonemura, et al. 2010. Metalloproteasedependent onset of blood circulation in zebrafish. Curr. Biol. 20:11101116. http://dx.doi.org/10.1016/j.cub.2010.04.052

Johnson, D.L., T.N. McAllister, and J.A. Frangos. 1996. Fluid flow stimulates rapid and continuous release of nitric oxide in osteoblasts. Am. J. Physiol. 271:E205-E208.

Kohn, A.D., and R.T. Moon. 2005. Wnt and calcium signaling: $\beta$-Cateninindependent pathways. Cell Calcium. 38:439-446. http://dx.doi.org/10 .1016/j.ceca.2005.06.022

Li, N., M.F. Diaz, and P.L. Wenzel. 2014. Application of fluid mechanical force to embryonic sources of hemogenic endothelium and hematopoietic stem cells. Methods Mol. Biol. In press. http://dx.doi/10.1007/7651_2014_95
Luis, T.C., B.A. Naber, P.P. Roozen, M.H. Brugman, E.F. de Haas, M. Ghazvini, W.E. Fibbe, J.J. van Dongen, R. Fodde, and F.J. Staal. 2011. Canonical wnt signaling regulates hematopoiesis in a dosage-dependent fashion. Cell Stem Cell. 9:345-356. http://dx.doi.org/10.1016/j.stem.2011.07.017

Lux, C.T., M. Yoshimoto, K. McGrath, S.J. Conway, J. Palis, and M.C. Yoder. 2008. All primitive and definitive hematopoietic progenitor cells emerging before E10 in the mouse embryo are products of the yolk sac. Blood. 111:3435-3438. http://dx.doi.org/10.1182/blood-2007-08-107086

McKinney-Freeman, S., P. Cahan, H. Li, S.A. Lacadie, H.T. Huang, M. Curran, S. Loewer, O. Naveiras, K.L. Kathrein, M. Konantz, et al. 2012. The transcriptional landscape of hematopoietic stem cell ontogeny. Cell Stem Cell. 11:701-714. http://dx.doi.org/10.1016/j.stem.2012.07.018

Merico, D., R. Isserlin, O. Stueker, A. Emili, and G.D. Bader. 2010. Enrichment map: a network-based method for gene-set enrichment visualization and interpretation. PLoS ONE. 5:e13984. http://dx.doi.org/10.1371/ journal.pone. 0013984

Mootha, V.K., C.M. Lindgren, K.F. Eriksson, A. Subramanian, S. Sihag, J. Lehar, P. Puigserver, E. Carlsson, M. Ridderstråle, E. Laurila, et al. 2003. PGC- $1 \alpha$-responsive genes involved in oxidative phosphorylation are coordinately downregulated in human diabetes. Nat. Genet. 34:267273. http://dx.doi.org/10.1038/ng1180

Nemeth, M.J., L. Topol, S.M. Anderson, Y. Yang, and D.M. Bodine. 2007. Wnt5a inhibits canonical Wnt signaling in hematopoietic stem cells and enhances repopulation. Proc. Natl. Acad. Sci. USA. 104:15436-15441. http://dx.doi.org/10.1073/pnas.0704747104

Nissim, S., R.I. Sherwood, J. Wucherpfennig, D. Saunders, J.M. Harris, V. Esain, K.J. Carroll, G.M. Frechette, A.J. Kim, K.L. Hwang, et al. 2014. Prostaglandin $E_{2}$ regulates liver versus pancreas cell-fate decisions and endodermal outgrowth. Dev. Cell. 28:423-437. http://dx.doi.org/ 10.1016/j.devcel.2014.01.006

North, T.E., W. Goessling, C.R. Walkley, C. Lengerke, K.R. Kopani, A.M. Lord, G.J. Weber, T.V. Bowman, I.H. Jang, T. Grosser, et al. 2007. Prostaglandin E2 regulates vertebrate haematopoietic stem cell homeostasis. Nature. 447:1007-1011. http://dx.doi.org/10.1038/nature05883

North, T.E., W. Goessling, M. Peeters, P. Li, C. Ceol, A.M. Lord, G.J. Weber, J. Harris, C.C. Cutting, P. Huang, et al. 2009. Hematopoietic stem cell development is dependent on blood flow. Cell. 137:736-748. http://dx.doi.org/10.1016/j.cell.2009.04.023

Ogasawara, A., T. Arakawa, T. Kaneda, T. Takuma, T. Sato, H. Kaneko, M. Kumegawa, and Y. Hakeda. 2001. Fluid shear stress-induced cyclooxygenase-2 expression is mediated by C/EBP $\beta$, cAMP-response element-binding protein, and AP-1 in osteoblastic MC3T3-E1 cells. J. Biol. Chem. 276:7048-7054. http://dx.doi.org/10.1074/jbc.M008070200

Ogawa, H., E. Kozhemyakina, H.H. Hung, A.J. Grodzinsky, and A.B. Lassar. 2014. Mechanical motion promotes expression of Prg4 in articular cartilage via multiple CREB-dependent, fluid flow shear stressinduced signaling pathways. Genes Dev. 28:127-139. http://dx.doi.org/ 10.1101/gad.231969.113

Ponik, S.M., and F.M. Pavalko. 2004. Formation of focal adhesions on fibronectin promotes fluid shear stress induction of COX-2 and $\mathrm{PGE}_{2}$ release in MC3T3-E1 osteoblasts. J. Appl. Physiol. 97:135-142. http:// dx.doi.org/10.1152/japplphysiol.01260.2003

Porter, R.L., M.A. Georger, O. Bromberg, K.E. McGrath, B.J. Frisch, M.W. Becker, and L.M. Calvi. 2013. Prostaglandin E2 increases hematopoietic stem cell survival and accelerates hematopoietic recovery after radiation injury. Stem Cells. 31:372-383. http://dx.doi.org/10.1002/stem.1286

Rangaswami, H., R. Schwappacher, T. Tran, G.C. Chan, S. Zhuang, G.R. Boss, and R.B. Pilz. 2012. Protein kinase G and focal adhesion kinase converge on Src/Akt/ $\beta$-catenin signaling module in osteoblast mechanotransduction. J. Biol. Chem. 287:21509-21519. http://dx.doi.org/10 $.1074 /$ jbc.M112.347245

Seta, F., A.D. Chung, P.V. Turner, J.D. Mewburn, Y. Yu, and C.D. Funk. 2009. Renal and cardiovascular characterization of COX-2 knockdown mice. Am. J. Physiol. Regul. Integr. Comp. Physiol. 296:R1751-R1760. http://dx.doi.org/10.1152/ajpregu.90985.2008

Shaywitz, A.J., and M.E. Greenberg. 1999. CREB: a stimulus-induced transcription factor activated by a diverse array of extracellular signals. Annu. Rev. Biochem. 68:821-861. http://dx.doi.org/10.1146/annurev biochem.68.1.821 
Smalt, R., F.T. Mitchell, R.L. Howard, and T.J. Chambers. 1997. Induction of $\mathrm{NO}$ and prostaglandin $\mathrm{E} 2$ in osteoblasts by wall-shear stress but not mechanical strain. Am. J. Physiol. 273:E751-E758.

Subramanian, A., P. Tamayo, V.K. Mootha, S. Mukherjee, B.L. Ebert, M.A. Gillette, A. Paulovich, S.L. Pomeroy, T.R. Golub, E.S. Lander, and J.P. Mesirov. 2005. Gene set enrichment analysis: a knowledge-based approach for interpreting genome-wide expression profiles. Proc. Natl. Acad. Sci. USA. 102:15545-15550. http://dx.doi.org/10.1073/pnas.0506580102

Sugimura, R., X.C. He, A. Venkatraman, F. Arai, A. Box, C. Semerad, J.S. Haug, L. Peng, X.B. Zhong, T. Suda, and L. Li. 2012. Noncanonical Wnt signaling maintains hematopoietic stem cells in the niche. Cell. 150:351-365. http://dx.doi.org/10.1016/j.cell.2012.05.041

Swiers, G., C. Baumann, J. O'Rourke, E. Giannoulatou, S. Taylor, A. Joshi, V. Moignard, C. Pina, T. Bee, K.D. Kokkaliaris, et al. 2013. Early dynamic fate changes in haemogenic endothelium characterized at the single-cell level. Nat. Commun. 4:2924. http://dx.doi.org/10.1038/ ncomms 3924

Topper, J.N., J. Cai, D. Falb, and M.A. Gimbrone Jr. 1996. Identification of vascular endothelial genes differentially responsive to fluid mechanical stimuli: cyclooxygenase-2, manganese superoxide dismutase, and endothelial cell nitric oxide synthase are selectively up-regulated by steady laminar shear stress. Proc. Natl. Acad. Sci. USA. 93:10417-10422. http:// dx.doi.org/10.1073/pnas.93.19.10417

Tsai, M.C., L. Chen, J. Zhou, Z. Tang, T.F. Hsu, Y. Wang, Y.T. Shih, H.H. Peng, N. Wang, Y. Guan, et al. 2009. Shear stress induces synthetic-to-contractile phenotypic modulation in smooth muscle cells via peroxisome proliferator-activated receptor alpha/delta activations by prostacyclin released by sheared endothelial cells. Circ. Res. 105:471480. http://dx.doi.org/10.1161/CIRCRESAHA.109.193656

Tsatsanis, C., A. Androulidaki, M. Venihaki, and A.N. Margioris. 2006. Signalling networks regulating cyclooxygenase-2. Int. J. Biochem.
Cell Biol. 38:1654-1661. http://dx.doi.org/10.1016/j.biocel.2006.03 .021

Uematsu, S., M. Matsumoto, K. Takeda, and S. Akira. 2002. Lipopolysaccharidedependent prostaglandin $\mathrm{E}_{2}$ production is regulated by the glutathionedependent prostaglandin $\mathrm{E}_{2}$ synthase gene induced by the Toll-like receptor 4/MyD88/NF-IL6 pathway. J. Immunol. 168:5811-5816. http://dx.doi.org/10.4049/jimmunol.168.11.5811

Wang, L., P. Zhang, Y. Wei, Y. Gao, R. Patient, and F. Liu. 2011. A blood flow-dependent klf2a-NO signaling cascade is required for stabilization of hematopoietic stem cell programming in zebrafish embryos. Blood. 118:4102-4110. http://dx.doi.org/10.1182/blood-2011-05-353235

Wang, X.L., A. Fu, S. Raghavakaimal, and H.C. Lee. 2007. Proteomic analysis of vascular endothelial cells in response to laminar shear stress. Proteomics. 7:588-596. http://dx.doi.org/10.1002/pmic.200600568

Yamamizu, K., T. Matsunaga, S. Katayama, H. Kataoka, N. Takayama, K. Eto, S Nishikawa, and J.K.Yamashita. 2012. PKA/CREB signaling triggers initiation of endothelial and hematopoietic cell differentiation via Etv2 induction. Stem Cells. 30:687-696. http://dx.doi.org/10.1002/stem.1041

Yoshimoto, M., E. Montecino-Rodriguez, M.J. Ferkowicz, P. Porayette, W.C. Shelley, S.J. Conway, K. Dorshkind, and M.C. Yoder. 2011. Embryonic day 9 yolk sac and intra-embryonic hemogenic endothelium independently generate a B-1 and marginal zone progenitor lacking B-2 potential. Proc. Natl. Acad. Sci. USA. 108:1468-1473. http://dx.doi.org/ 10.1073/pnas.1015841108

Yu, Y., J. Fan, Y. Hui, C.A. Rouzer, L.J. Marnett, A.J. Klein-Szanto, G.A. FitzGerald, and C.D. Funk. 2007. Targeted cyclooxygenase gene (ptgs) exchange reveals discriminant isoform functionality. J. Biol. Chem. 282 1498-1506. http://dx.doi.org/10.1074/jbc.M609930200

Zhang, Y., and Y. Daaka. 2011. PGE2 promotes angiogenesis through EP4 and PKA C $\gamma$ pathway. Blood. 118:5355-5364. http://dx.doi.org/ 10.1182/blood-2011-04-350587 